\title{
Long-Term Homogeneity and Trends of Hydroclimatic Variables in Upper Awash River Basin, Ethiopia
}

\author{
Mekonnen H. Daba, ${ }^{1,2,3}$ Gebiaw T. Ayele, ${ }^{4}$ and Songcai You ${ }^{1}{ }^{1}$ \\ ${ }^{1}$ Institute of Environment and Sustainable Development in Agriculture (IEDA), \\ Chinese Academy of Agricultural Sciences (CAAS), 100081 Beijing, China \\ ${ }^{2}$ Oromia Agricultural Research Institute, Bako Agricultural Research Center, Bako, Ethiopia \\ ${ }^{3}$ Graduate School of Chinese Academy of Agricultural Sciences, 100081 Beijing, China \\ ${ }^{4}$ Australian Rivers Institute and School of Engineering, Griffith University, Nathan, Queensland 4111, Australia
}

Correspondence should be addressed to Songcai You; yousongcai@caas.cn

Received 1 June 2020; Revised 13 October 2020; Accepted 24 October 2020; Published 24 November 2020

Academic Editor: Gabriele Buttafuoco

Copyright (c) 2020 Mekonnen H. Daba et al. This is an open access article distributed under the Creative Commons Attribution License, which permits unrestricted use, distribution, and reproduction in any medium, provided the original work is properly cited.

\begin{abstract}
Understanding long-term trends in hydroclimatic variables is important for future sustainable water resource management as it could show the possible regime shifts in hydrology. The main objective of this study was to analyze the homogeneity and trends of hydroclimatic data of Upper Awash Sab-Basin (UASB) in Oromia, Ethiopia, by employing homogeneity tests and Mann-Kendall and Sen's slope tests. The data consist of 18 rainfall stations, 8 temperature stations, and 8 flow gauging stations across the UASB. Homogeneity and trends in streamflow, rainfall, and temperature variables were analyzed for the time period 1980 to 2017 . In order to analyze homogeneity of hydroclimatic variables, we used four homogeneity tests (Pettitt's test, Buishand's test, standard normal homogeneity test, and von Neumann ratio test) at 5\% significance level. Based on the outputs of four homogeneity tests, the results were classified into three categories, namely, "useful," "doubtful," and "suspect" to select the homogeneity stations. Mann-Kendall $(Z)$ and Sen's slope tests $(Q)$ were applied for the selected homogeneous time series to detect the trend and magnitude of changes in hydroclimatic variables. The result showed that most of the stations in annual rainfall and streamflow data series were classified as useful. It is found that $58 \%$ of the rainfall stations were homogeneous. It is highlighted that 3 out of 8 discharge gauging stations have an inhomogeneity as they failed from one or a combination of the four tests. The MK revealed significant decreasing trends of annual rainfall in Addis Alem $(Q=-19.81)$, Akaki $(Q=-5.60)$, Hombole $(Q=-9.49)$, and $G$ hinch $(Q=-12.38)$ stations. The trend of annual temperature was a significant increasing trend in Addis Ababa Bole $(Q=0.05)$, Addis Ababa Tikur Ambessa $(Q=0.03)$, Tulu Bolo $(Q=0.07)$, and Addis Alem $(Q=0.06)$ stations. The results of discharge showed a significant increasing trend in Bega at Mojo $(Q=0.17)$ and Hombole $(Q=0.03)$ gauging stations. In general, the results obtained from discharge, rainfall, and temperature series indicated that most of the stations exhibited no trends in both annual and seasonal time series. It can be concluded that decreases in average annual rainfall totals and increases in mean annual temperature will probably drive sub-basin scale changes in discharge. We believe that the results obtained can fill information gaps on homogeneity and trends of hydroclimatic variables, which is very crucial for future water resource planning and management in the face of climate change.
\end{abstract}

\section{Introduction}

Climate change impacts will felt through altering patterns of agricultural production and water availability, with an increase in temperature and changing the rainfall patterns. The climate of the Earth has been changing through time [1].
According to Intergovernmental Panel on Climate Change (IPCC) assessment reports (2014), for instance, compared to any preceding decade since 1850 , Earth's surface temperature has been reported to be successively warmer for the last three decades [2]. It was also reported that the period 1983 to 2012 was likely the warmest compared to the last 1400 years' 
temperature variation in the Northern Hemisphere. This indicates that it is in recent years that the effect of climate change has been felt through abrupt changes in hydroclimatic system at various spatial scales, agricultural production, and water availability $[3,4]$. The change in both local and global climate, magnitude, and pattern of temperature and rainfall affect the rate and occurrence of hydrologic phenomena such as drought and flood. According to the Fifth Assessment Report of the IPCC, the global warming is anincreasing trend in the global average temperature by $0.74^{\circ} \mathrm{C} \pm 0.18^{\circ} \mathrm{C}$ over the last 100 years (1906-2005) and likely a decreasing trend in annual rainfall [5]. In Africa, average precipitations have shown declining trends while increasing trends in average temperature, and in the future, the temperature in Africa is likely to grow more rapidly than in other regions, which could exceed $4^{\circ} \mathrm{C}$ at the end of the 21st century [2].

Globally, rainfall and temperature are among the most key climate variables which control and determine agricultural production activities in the 21st century [6-8]. For instance, climate extremes (drought and flood) accounted for about $18-43 \%$ of interannual variations in global crop yield [9]. As a subject of abrupt climate change studies, change detection and trend analysis in hydroclimatic time series have received growing attention over the years [10-12]. Thus, rainfall and temperature trend analysis often helps to recognize the magnitude and extent of climate change [2]. For example, in most African countries, particularly in Ethiopia, analyses of temporal and spatial climate variables including its trend are very crucial for sustainable agricultural and water management [13-17]. Due to changes in precipitation and temperature, the scarcity of water resources may become more severe $[18,19]$ and may greatly affect the hydrological system [20]. In response to change in climate, there is a marked tendency towards a decrease in the water resources and with a consistent increase in drought severity and duration [21]. Characterizing precipitation and flow trends is crucial for any design of sustainable water management strategies and to reduce the impact of droughts and floods [18, 22, 23].

An understanding of climate trends, variability, and prediction is very important for hydroclimatic studies in highly vulnerable areas $[9,22,24-28]$. However, before conducting researches related to changes in climate, agricultural system, hydrology, and water resources, data have to be checked for reliability and inhomogeneities. The interpretation of inhomogeneous data may lead to incorrect conclusions. In this regard, reliability of empirically observed data should be tested before application and further analysis to avoid ambiguous trend results [29]. In this context, conducting time series homogeneity tests before running any climate-driven hydrological model determines the reliability of our model prediction [30]. Thus, homogeneity tests of data series will help for the hydroclimaticrelated studies. Time series data homogeneity tests can be classified into two groups, the absolute and relative methods [30]. The absolute test is applied for each station separately, whereas, in the relative method, the neighboring (reference) stations are used in testing the homogeneity of data series. As the study report showed, homogeneity analysis results depend on the selected test variable, the test algorithm, and the chosen significance level [29]. The commonly used absolute homogeneity tests to detect inhomogeneities in the hydrometeorological time series are the Pettitt's test, the standard normal homogeneity test, the Buishand range test, and the von Neumann ratio test [30-35]. To evidence the degree of applicability of homogeneity test in hydrology, several studies have been done on the homogeneity test to detect and check inhomogeneities of data in the different regions of the world [25, 29, 36-40]. Meteorological data homogeneity analysis is the basis for the quantitative assessment of climate change and underpins the reliability of any inferences [41, 42].

The applications of statistical tests were very important to determine homogeneity and trends in the climatic series [39]. Though limited information was reported on the trend analyses of hydroclimatological data series in Awash River Basin, e.g., the work of $[23,43]$, no information is available on the homogeneity analyses of data series in the study area. Thus, before conducting any climatic analysis, the homogeneity of the time series must be confirmed and any inhomogeneous series must be detected, adjusted, or removed from the analysis [30]. Hence, evaluation of homogeneity tests is usually performed on the total annual precipitation data [44].

Climate time series analysis and modeling is one of the major tools used to detect and analyze change in climatic variables [18, 45-47]. Since modern agriculture was introduced, the Awash River Basin has been the most extensively developed and used river basin in Ethiopia, and thus, assessing the trends of climate and discharges in the Awash River Basin is very essential for the management of water resources for future socio-economic development $[23,43]$. In view of that, Gedefaw et al. [43] conducted climatic and hydrological trend analysis in the Awash River Basin. They mainly found decreasing trends in precipitation and discharge, while increasing trends were detected for temperature. Similarly, the study reported by [23] highlighted the predictability of time series changes in seasonal and annual rainfall and discharge from changes in hydroclimatic variables. Furthering the finding, Worku et al. [28] observed changes in daily rainfall and temperature extremes in the Upper Blue Nile Basin, Ethiopia, which showed that due to change in observed climate trends and extreme events, the signs of climate change were detected over the study area. In the past few years, several studies have been focused on the climatic and hydrological trend analysis over the country [23, 24, 43, 48, 49] using Mann-Kendall and Sen's slope tests. They found that there has been a significant change in rainfall and temperature trends. However, no studies have been reported in the Upper Awash Sab-Basin (UASB) for investigating both homogeneity and trend of discharge and rainfall, using time series analysis simultaneously. To address these information gaps, due consideration needs to be given to the data quality control and homogeneity test before conducting any climatic and hydrological studies for future water resource management and planning.

The objective of this study was to analyze the homogeneity and trend of UASB hydroclimatic data from 1980 to 
2017 by employing homogeneity, Mann-Kendall, and Sen's slope tests on the seasonal and annual rainfall, temperature, and discharge data. This remaining portion of the paper is organized into materials and methods, results and discussion, and conclusion. The materials and methods section introduces description of the study area and meteorological and hydrological datasets, as well as the statistical approaches of homogeneity and trend testing. The outcomes of the homogeneity and trend analysis, the monthly and annual discharge, and rainfall and their temporal changes, as well as annual and seasonal hydroclimatic trends are described in the results and discussion section followed by conclusions based on the obtained results.

\section{Materials and Methods}

2.1. Study Area. This study was undertaken on the upper part of the Awash River Basin in Ethiopia that is located between $8^{\circ} 16^{\prime}$ and $9^{\circ} 18^{\prime}$ north latitude and between $37^{\circ} 57^{\prime}$ and $39^{\circ} 17^{\prime}$ east longitude with altitude varying from 1580 to $3396 \mathrm{~m}$ from the above mean sea level (Figure 1). Upper Awash sub-basin has been selected for the study of homogeneity and trend detection in hydroclimatic variables due to change in climate and human-induced interferences, because of urbanization, rapid population growth, and industrialization in the area. The UASB shares its boundaries with the Upper Blue Nile Basin in the northwest, middle Awash Sab-Basin in the east, Omo Gibe and rift valley in the west, and Wabi Shebelle Basin in the south, respectively. The sub-basin area covers a surface of about $7656 \mathrm{~km}^{2}$. Awash River is among the main sources of water supply for the central rift valley of Ethiopia. The mean annual rainfall over the basin reaches a value of $1030 \mathrm{~mm}$ and the temperature for the time period of 1980-2010, the minimum and maximum mean value, and the average of minimum and maximum values are $10.16^{\circ} \mathrm{C}, 25.05^{\circ} \mathrm{C}$, and $17.60^{\circ} \mathrm{C}$, respectively [49].

2.2. Data. Eighteen meteorological stations and eight hydrological gauges were considered in the analyses. Available meteorological data of daily time period 1980-2017, including rainfall and minimum and maximum temperature data were obtained from the National Meteorology Agency (NMA) of Ethiopia. For this data analyses, a time series of no missing values were selected at each station. The location of the meteorological and discharge gauging stations in the sub-basin are shown in Figure 2 and the general information of meteorological and discharge stations is listed in Table 1. The discharge data were collected from Ethiopian Ministry of Water Resources (MoWR). Meteorological and hydrological data analyses were conducted at each of the UASB stations. The latitude, longitude, elevation, and mean annual discharge of eight gauging stations are listed in Table 2.

2.3. Statistical Methods. Data inhomogeneity can affect assessment of hydroclimatic extremes and trends. In this study, three statistical approaches were used to analyse the homogeneity and the trend in hydroclimatic time series.
First, the absolute homogeneity tests analyses of the annual and seasonal discharge and rainfall time series were performed at each station for the entire basin. Second, the MK and Sen's slope tests have been applied to the selected homogeneous time series of annual and seasonal discharge, rainfall, and temperature to determine increasing or decreasing trends in the data series. The rainfall, temperature, and discharge data analyses were performed based on annual and three seasonal periods, Kiremt (June-September), Bega (October-January), and Belg (February-May), as this helps to provide a seasonal comparison of changes in the hydroclimatic variables.

2.4. Homogeneity Test. Hydroclimatic homogeneity tests allow detecting a change along with a time series data $[36,50]$. As it supports the consistency of any inferences, homogeneity testing is one of the most important analyses in climate-related studies [42]. It is very crucial to carry out different hydroclimatic homogeneity tests, before applying any climate impact studies. Using unreliable observed meteorological data for hydrological and climate studies might lead to wrong conclusions, thereby suggesting data homogeneity tests and data quality control. Homogeneity test analysis depends on the chosen significance level, test algorithm, and test variable [29]. For instance, Wijngaard et al. [40] used four homogeneity tests, viz., standard normal homogeneity test (SNHT), Pettitt's test, Buishand range test (BRT), and von Neumann ratio (VNR) tests to assess the European climate conditions. Similarly, in this study, we used these four homogeneity tests to minimize unreliability issues due to data inhomogeneity and to detect and remove the inhomogeneous stations for the trend analysis of hydroclimatic variables.

2.4.1. Buishand's Test (BRT). Buishand's test [32] supposes that tested values are independent and identically normally distributed (null hypothesis), whereas the alternative hypothesis assumes that the series has a jump-like shift or break [51]. This test is more sensitive to breaks in the middle of the time series [37]. The test statistics, which are the adjusted partial sums [32], are defined as

$$
S_{K}^{*}=\frac{n \sum_{i=1}^{k}\left(Y_{i}-\bar{Y}\right)}{\sum_{i=1}^{n}\left(Y_{i}-\bar{Y}\right)^{2}}, \quad k=1,2, \ldots, n .
$$

When series are homogeneous, the values of $S_{K}^{*}$ will fluctuate around zero because no systematic deviations of the $Y_{i}$ values with respect to their mean will appear. Qstatistics: if a break is present in year $K$, then $S_{K}^{*}$ reaches a maximum (negative shift) or minimum (positive shift) near the year $k=K$.

$$
Q=\max _{1 \leq k \leq n} S_{K}^{*}
$$

$R$-statistics (range statistics) are

$$
R=\left(\max _{1 \leq k \leq n} S_{K}^{*} \cdots \max _{1 \leq k \leq n} S_{K}^{*}\right) .
$$

Accordingly, Buishand [32] gave critical values for $Q$ and $R$ for different dataset lengths. 


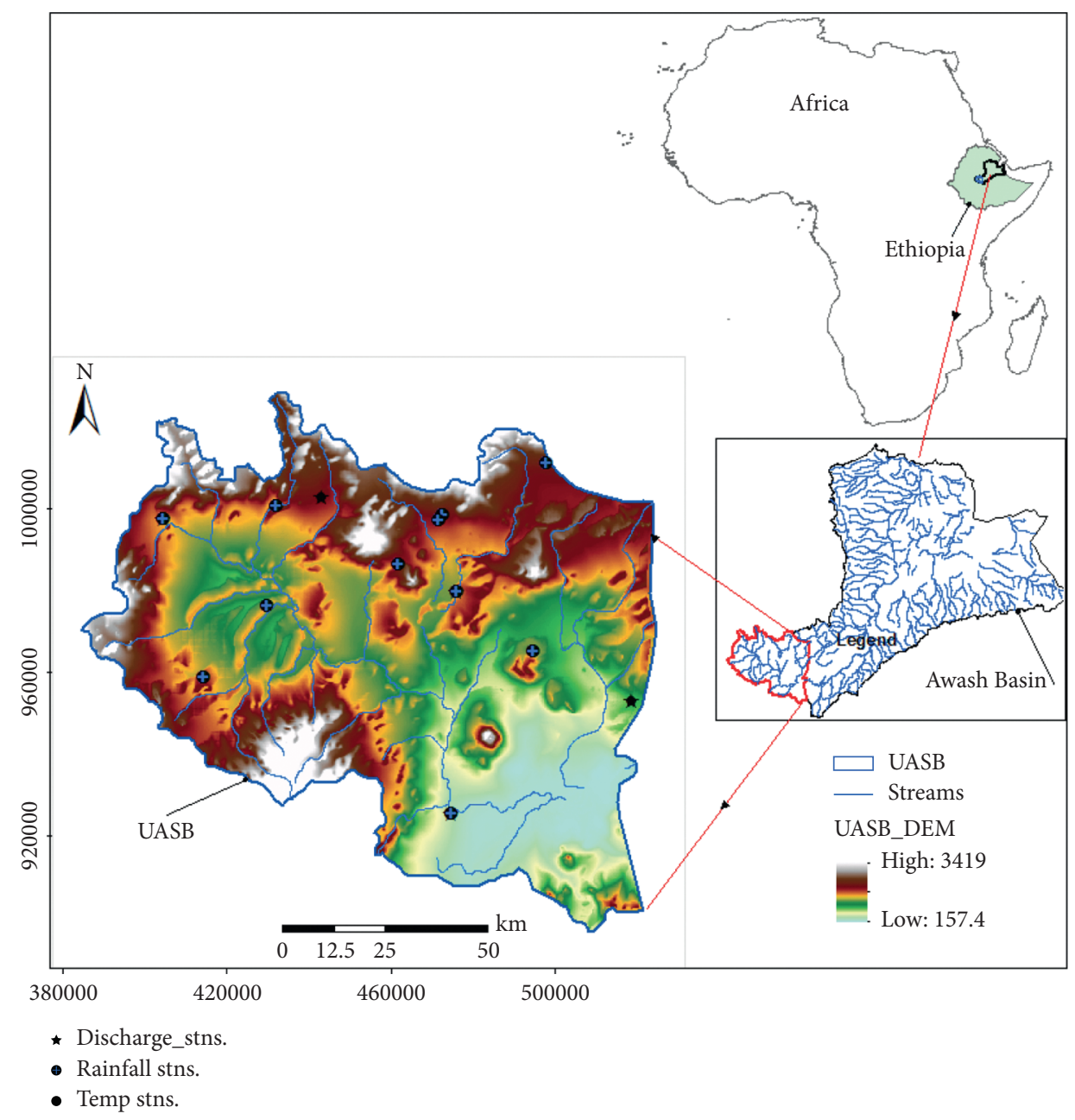

FIgURE 1: Study area location in the Upper Awash River Basin of central rift valley of Ethiopia.

2.4.2. Pettitt's Test. The Pettitt's test [34] is a nonparametric test adapted from the rank-based Mann-Whitney test that permits detecting the point at which the shift occurs in a time series. Pettitt's test is more sensitive to the breaks in the middle of the series [37]. The ranks $R_{1}, \ldots, R_{n}$ of the $Y_{1}, \ldots$, $Y_{n}$ are used to calculate the statistics:

$$
X_{k}=2 \sum_{i=1}^{k} r_{i}-k(n+1), \quad k=1,2, \ldots, n .
$$

If a break occurs in year $K$, then the statistic is maximal or minimal near the year $k=K$ :

$$
X_{K}=\max _{1 \leq k \leq n}\left|X_{k}\right|
$$

2.4.3. Standard Normal Homogeneity Test (SNHT). The SNHT [52] is one of the most popular likelihood ratio tests in climate and hydrology studies used to detect inhomogeneities in climatological, hydrological, and any other time series. In this test, the alternative and null hypotheses are the same as in the Buishand's test. However, unlike the Buishand's test, SNHT is more sensitive to the breaks at the beginning and end of the time series [30, 37, 53]. A statistic $T(k)$ compares the mean of the first $k$ years of the record with that of the last $(n-k)$ years; Alexandersson and Moberg [31] proposed a statistic $T(k)$ as follows:

$$
\begin{aligned}
T(k) & =k z_{1}^{2}+(n-k) z_{2}^{2}, \quad 1 \leq k \leq n, \\
Z_{1} & =\frac{1}{K} \frac{\sum_{i=1}^{k}\left(Y_{i}-\bar{Y}\right)}{S}, \\
Z_{2} & =\frac{1}{n-k} \frac{\sum_{i=k+1}^{n}\left(Y_{i}-\bar{Y}\right)}{S} .
\end{aligned}
$$

$S$ is the estimated standard deviation. If a break is located at the year $K$, then $T(k)$ reaches a maximum near the year $k=K$. The test statistic $T_{0}$ is defined as

$$
T_{0}=\max _{1 \leq k \leq n}\left|T_{k}\right| .
$$

The probability of rejecting the null hypothesis when $T_{0}$ exceeds a certain critical value depends on the sample size $[30,31]$. Then, the series would be classified as inhomogeneous at a $95 \%$ level of significance. 


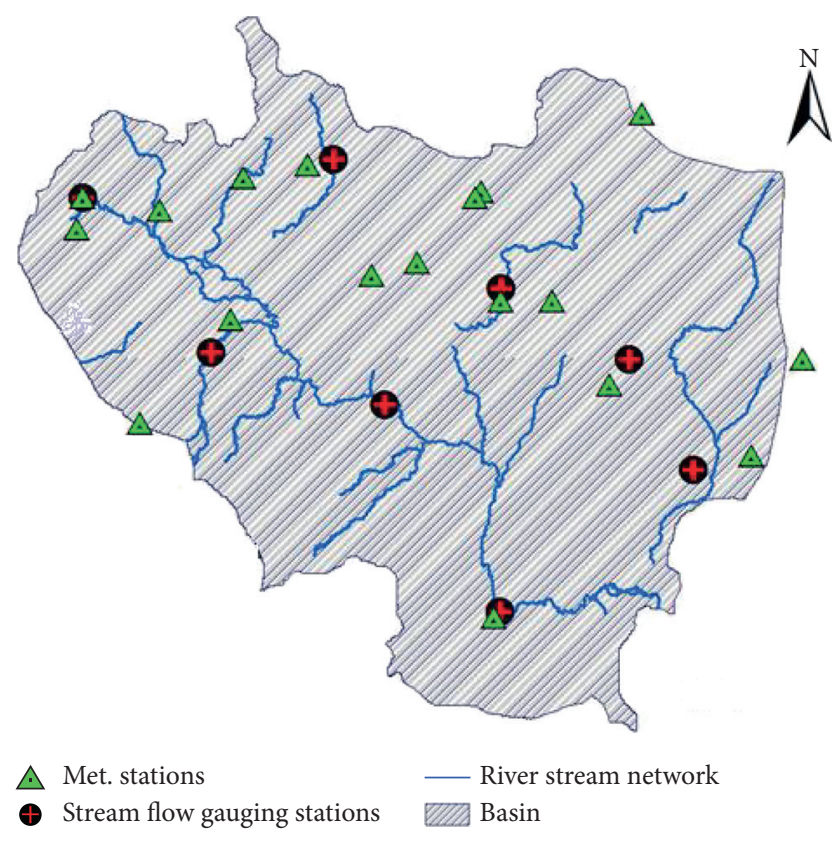

FIGURE 2: Location map of meteorological and discharge gauging stations in the UASB.

2.4.4. von Neumann Ratio Test (VNRT). The VBR [35] is a nonparametric test most widely used to detect nonhomogeneity in time series. In this test, the null hypothesis is that the data are independent identically distributed random values, whereas the alternative hypothesis is that the values in the series are not randomly distributed. The test does not give any information about the point of a break but provides an estimation of the overall level of inhomogeneity in the data. The von Neumann ratio $N$ is defined as the ratio of the mean square successive (year to year) difference to the variance:

$$
N=\frac{\sum_{i=1}^{n-1}\left(Y_{i}-Y_{i+1}\right)^{2}}{\sum_{i=1}^{n}\left(Y_{i}-\bar{Y}\right)^{2}}
$$

Hereafter, for each of the test descriptions, $n$ is the dataset length, $Y_{i}$ is the Ith element of the dataset, and $\bar{Y}$ is the mean value of the dataset. When the sample is homogeneous, the expected value is $N=2$. If the sample contains a break, then the value of $N$ tends to be lower than this expected value. If the sample has rapid variations in the mean, then values of $N$ may rise above two [54]. In this study, according to [40] recommendation, critical values of 1.50 , $107,7.65$, and 1.42 are used for BRT, Pettitt's test, SNHT, and VBR test, respectively.

2.4.5. Evaluation of Homogeneity Tests. In this study, absolute homogeneity tests of the total annual rainfall and mean annual streamflow time series were used to find inhomogeneity in the datasets. Based on the results obtained from four homogeneity tests, according to the methods proposed by [40], the statistical test results were categorized into three classes, which are "useful," "doubtful," and "suspect." After individually tested, each of the hydroclimatic variables and their categories (useful, doubtful, and suspect) were combined for a final evaluation of the usefulness of time series. This can be described as the series that rejects one or none categorized as "useful," the series that rejects two null hypotheses categorized as "doubtful," and the series that rejects three or all tests of null hypothesis under the four tests at 5\% significance level categorized as "suspect" $[26,40,55]$. Based on the alpha value of 0.05 (95\% confidence level), if the $P$ value is greater than alpha value, therefore, the series is homogeneous. The SNHT, BR test, and Pettitt's test assume the series consisted of break, and on the other hand, VNR cannot detect the year of the break because the series is not randomly distributed under the alternative hypothesis [30]. The estimation of the usefulness of rainfall and streamflow time series was derived from the individual assessment of four homogeneity tests, and this integrated evaluation was used for trend analysis and interpretation of changes in selected annual and seasonal hydroclimatic variables.

2.4.6. Trend Analyses. We used the modified Mann-Kendall trend [56] mainly developed from Mann-Kendall $[57,58]$. Mann-Kendall (MK) and Sen's slope tests were applied for the selected homogeneous hydrological and meteorological variables. Trend analysis is an effective method to detect changes in climatic and hydrological variables $[14,16,20,26,55,59-61]$. The Mann-Kendall test has been widely used to detect trends in reference evapotranspiration, streamflow, temperature, and precipitation time series in different regions around the world [14, 15, 23, 24, 47, 62-65]. In this study, a modified Mann-Kendall trend test was used to detect the change in streamflow, rainfall, and average temperature. Mann-Kendall trend test and Sen's slope were used to evaluate the trend of streamflow, mean annual temperature, and rainfall in the area. The Mann-Kendall statistic of the time series data analyzes the output, compared to the critical value to test whether the trend of the hydroclimatic variables has been detected or not. Data for performing the Mann-Kendall analysis should be in a time sequential order. The first step is to determine the sign of the difference between consecutive sample results. Sgn $\left(X_{j}-X_{k}\right)$ is an indicator function that results in the values 1,0 , or -1 according to the sign of $X_{j}-X_{k}$ where $j>k$. A positive value is an indicator of an increasing (upward) trend and a negative value is an indicator of decreasing (downward) trend. The MK statistic (S) is given by the following equations:

$$
\begin{gathered}
S=\sum_{i=1}^{n-1} \sum_{j=i+1}^{n} \operatorname{sgn}\left(x_{j}-x_{i}\right), \\
\operatorname{sgn}\left(x_{j}-x_{i}\right)= \begin{cases}+1, & \text { if }\left(x_{j}-x_{i}\right)>0, \\
0, & \text { if }\left(x_{j}-x_{i}\right)=0, \\
-1 & \text { if }\left(x_{j}-x_{i}\right)<0,\end{cases}
\end{gathered}
$$

where $x_{j}$ and $x_{i}$ represent the data points in period $j$ and $i$. While the amount of data series is larger than or equivalent 
TABLE 1: General information of meteorological stations.

\begin{tabular}{|c|c|c|c|c|c|c|}
\hline No & Station & Latitude $\left({ }^{\circ} \mathrm{N}\right)$ & Longitude $\left({ }^{\circ} \mathrm{E}\right)$ & Elevation $(\mathrm{m})$ & Annual mean rainfall $(\mathrm{mm})$ & Average temperature $\left({ }^{\circ} \mathrm{C}\right)$ \\
\hline 1 & Addis Ababa Bole & 9.03 & 38.75 & 2354 & 1069.1 & 16.5 \\
\hline 2 & A. A. Tikur Ambessa & 9.02 & 38.74 & 2386 & 1215.4 & 17.2 \\
\hline 3 & Addis Alem & 9.05 & 38.38 & 1600 & 1096.5 & 16.9 \\
\hline 4 & Akaki & 8.86 & 38.78 & 2057 & 975.6 & 19.9 \\
\hline 5 & Debrezeit & 8.73 & 38.95 & 1900 & 852.3 & 19.1 \\
\hline 6 & Holeta & 9.07 & 38.48 & 2380 & 1037.9 & 14.5 \\
\hline 7 & Mojo & 8.62 & 39.17 & 1870 & 967.9 & 20.3 \\
\hline 8 & Tulu Bolo & 8.67 & 38.22 & 2100 & 1158.6 & 17.2 \\
\hline 9 & Dertu Liben & 8.97 & 38.12 & 1991 & 739.3 & $*$ \\
\hline 10 & Ejere & 8.77 & 39.25 & 2245 & 881.9 & $*$ \\
\hline 11 & Ghinch & 9.02 & 38.13 & 2132 & 1149.9 & * \\
\hline 12 & Guranda Meda & 8.90 & 38.58 & 2187 & 1097.9 & $*$ \\
\hline 13 & Hombole & 8.37 & 38.77 & 1665 & 912.9 & $*$ \\
\hline 14 & Sebeta & 8.92 & 38.65 & 2240 & 1149.6 & $*$ \\
\hline 15 & Sendafa & 9.15 & 39.00 & 2560 & 1090.4 & $*$ \\
\hline 16 & Teji & 8.83 & 38.36 & 2091 & 939.7 & $*$ \\
\hline 17 & Welenkomi & 9.00 & 38.25 & 2165 & 999.5 & $*$ \\
\hline 18 & Zequela & 8.86 & 38.86 & 3050 & 1204.3 & $*$ \\
\hline Average & & & & & 1029.9 & 17.7 \\
\hline
\end{tabular}

${ }^{*}$ Data not available (the station that has no temperature recording stations).

TABLe 2: General information of discharge gauging stations.

\begin{tabular}{lccccc}
\hline No & Station & Latitude $\left({ }^{\circ} \mathrm{N}\right)$ & Longitude $\left({ }^{\circ} \mathrm{E}\right)$ & Elevation $(\mathrm{m})$ & Mean annual percentage $\left(\mathrm{m}^{3} / \mathrm{s}\right)$ \\
\hline 1 & M. Kunture & 8.70 & 38.60 & 2332 & 30.87 \\
2 & Hombole & 8.38 & 38.78 & 2300 & 43.59 \\
3 & Holeta & 9.08 & 38.52 & 2322 & 1.46 \\
4 & Mojo & 8.60 & 39.08 & 2175 & 5.51 \\
5 & Akaki & 8.88 & 38.78 & 2100 & 18.17 \\
6 & Teji & 8.63 & 38.28 & 2415 & 3.13 \\
7 & Ghinch & 9.03 & 38.15 & 2370 & 1.05 \\
8 & Melka Sedi & 8.77 & 38.98 & 2125 & 62.84 \\
\hline
\end{tabular}

to ten $(n \geq 10)$, since $n \geq 10$, the MK test is then categorized by a standard distribution with the mean $E(S)=0$ and variance $\operatorname{Var}(S)$ is given as

$$
\operatorname{Var}(S)=\frac{n(n-1)(2 n+5)-\sum_{k=1}^{m} t_{k}\left(t_{k}-1\right)\left(2 t_{k}+5\right)}{18}
$$

where $m$ is the number of the tied groups in the time series and $t_{k}$ is the number of ties in the $k$ th tied group. From this, the test $Z$ statistics is obtained using an approximation as follows:

$$
Z= \begin{cases}\frac{s-1}{\sqrt{\operatorname{Var}(S)},} & \text { if } S>0, \\ 0, & \text { if } S=0, \\ \frac{s+1}{\sqrt{\operatorname{Var}(S)},}, & \text { if } S<0 .\end{cases}
$$

In a $Z$ test, the null hypothesis $\left(H_{o}\right)$ implies no trend and the alternative hypothesis $\left(H_{a}\right)$ means a significant change in time series. The positive $Z$ value indicates an increasing trend, whereas the negative $z$ value indicates a decreasing trend. A significant trend at $0.1,0.05$, and 0.01 significance levels exist when the $|Z|>1.645,|Z|>1.96$, and $|Z|>2.576$, respectively [66]. Therefore, in this study, 90, 95, and $99 \%$ confidence levels were applied to analyse the hypothesis.

2.4.7. Sen's Slope Trend Detection. The magnitude of the detected trends was calculated using the Sen's slope test $[67,68]$. Several studies used the Sen's slope estimator for trend detection $[15,23,43,55]$. This test computes both the slope (i.e., linear rate of change) and intercept according to Sen's method. First, a set of linear slopes is calculated as follows:

$$
d_{k}=\frac{Y_{j}-Y_{i}}{j-i}
$$

for $(1 \leq i<j \leq n)$, where $d$ is the slope, $Y$ denotes the variable, $n$ is the number of data, and $i, j$ are indices.

Sen's slope is then calculated as the median from all slopes: $\beta=$ Median $\left(d_{k}\right) . \beta$ positive means the trend is increasing whereas $\beta$ negative means a decreasing trend. 


\section{Results}

Monthly and annual data from each rainfall and streamflow station are tested by the four homogeneity tests (Pettitt's, SNHT, BRT, and VNR). The annual and seasonal temporal trend analysis of rainfall, temperature, and streamflow time series were performed using Mann-Kendall methods at a 5\% level of significance at each station. The monthly and annual homogeneity tests analyses were followed by spatial-temporal trend analyses of selected seasonal and annual hydroclimatic time series.

\subsection{Monthly Rainfall Homogeneity Test Results}

3.1.1. SNHT. The critical values of the SNHT results are shown in Figure 3(a). In this study, according to [40], the critical value of $T_{0}=7.65$ was considered at a $95 \%$ confidence level for the given sample size. Thus, the estimated statistical test for the monthly data series lower than this value was considered as homogeneous. As shown in Figure 3(a), except at Debre Zeit, Sebeta, Sendafa, and Addis Ababa Tikur Ambessa stations, the rainfall data series reveals inhomogeneity in one or more months in all remaining stations. The results revealed that rainfall time series for the months of January and December were found homogeneous at all stations. The SNHT statistics estimated for the rainfall time series at Dertu Liben, Ejere, Guranda Meda, Holeta, Mojo, Welenkomi, and Zequala stations were higher than the critical value in most months, whereas the remaining stations were lower than the critical value, except for a few months. It was found that inhomogeneity was detected at different stations in different months. For instance, the rainfall time series were found inhomogeneous in November at the Addis Ababa Bole, October at Akaki and Tulu Bolo, May at Ghinch, and May and August at Hombole stations. Moreover, inhomogeneity was detected at Dertu Liben, Zequala, and Welenkomi in ten months, at Ejere and Mojo in nine months, and at Guranda Meda and Holeta in eight months under the SNHT test.

3.1.2. Pettitt's Test. The critical values of the Pettitt's test results of each station are shown in Figure 3(b). The critical value of the test statistics $\left(X_{k}=107\right)$ at a $95 \%$ confidence level was used to determine the homogeneity of rainfall data series. If the critical value is higher than the estimated statistical test, the rainfall data series was considered as homogeneous, whereas, if the test statistic is higher than the critical value, the data series was considered as inhomogeneous. As shown in Figure 3(b), the Pettitt's test statistics estimated for the monthly rainfall time series at Addis Alem, Akaki, Ghinch, Hombole, Sebeta, Teji, and Tulu Bolo stations were lower than the critical value in all months. Monthly rainfall data series at stations in Sendafa, Debre Zeit, Addis Ababa Tikur Ambessa, and Addis Ababa Bole were found inhomogeneous for a few months as the estimated test statistics was higher than the critical value. The monthly rainfall time series were found inhomogeneous in February and November at the Addis Ababa Bole, in August at Addis Ababa Tikur Ambessa, in February, May, and June at Debre Zeit, and in February, March, and June at Sendafa stations. Inhomogeneity was detected at Dertu Liben, Holeta, Guranda Meda, and Ejere in nine months, at Mojo in ten months, and at Zequala and Welenkomi stations in eleven months under the Pettitt's test.

3.1.3. Buishand's Test. The results of the Buishand's test obtained for monthly rainfall time series at selected stations are shown in Figure 3(c). The critical value of the test statistics threshold line at $Q=1.50$ was used to identify homogeneity in monthly rainfall time series at a $95 \%$ confidence level. The estimated test statistics higher than 1.50 values were considered as inhomogeneous. Similar to the SNHT and Pettitt's test inhomogeneity was detected in monthly rainfall time series for December at most stations. As it is shown in the figure, the Buishand's test detected homogeneous monthly rainfall series for most of the stations, except at Dertu Liben, Ejere, Guranda Meda, Holeta, Mojo, Welenkomi, and Zequala. The Addis Ababa Bole rainfall time series was found inhomogeneous in March, June, July, August, September, and December, while the Addis Ababa Tikur Ambessa station data were found inhomogeneous in June, July, October, and November. Rainfall data series were found homogeneous for most of the stations, except for few months in April, July, and September at the Addis Alem; in June, July, September, November, and December at Akaki; in April and November at Debre Zeit, in May and June at Debre Zeit, in July and November at Ghinch; in July at Hombole, in April, August, September, and November at Sebeta; in January and November at Sendafa, in March and November at Teji, in January and July at Tulu Bolo stations. Overall, monthly rainfall time series of eleven months at Mojo and Welenkomi, ten months at Dertu Liben and Ejere, nine months at Guranda Meda, eight months at Holeta and Zequala stations were found inhomogeneous under Buishand's test. Comparing to the SNHT and Pettitt's tests, the Buishand's test found inhomogeneous time series data in more stations.

3.1.4. von Neumann's Test. The results of von Neumann's test obtained for monthly rainfall time series at each station are given in Figure 3(d). As shown in the figure, the von Neumann's test result has two threshold lines. The threshold line of this test at $N=1.42$ value was used to identify homogeneity in monthly rainfall data series at a 95\% confidence level. The critical value of the estimated test statistics for the rainfall data series less than 1.42 was considered homogeneous, whereas higher than this value were considered inhomogeneous data series. The VNR test statistics estimated for the monthly rainfall data series at Dertu Liben, Ejere, Guranda Meda, Holeta, Mojo, Welenkomi, and Zequala stations are higher than the critical value in most of the months, whereas in the remaining stations, homogeneous data series were found for most of the months except for a few months. It can be noted that inhomogeneity was detected in rainfall data series in one or more months in every station. The threshold line of test statistics above 2.0 


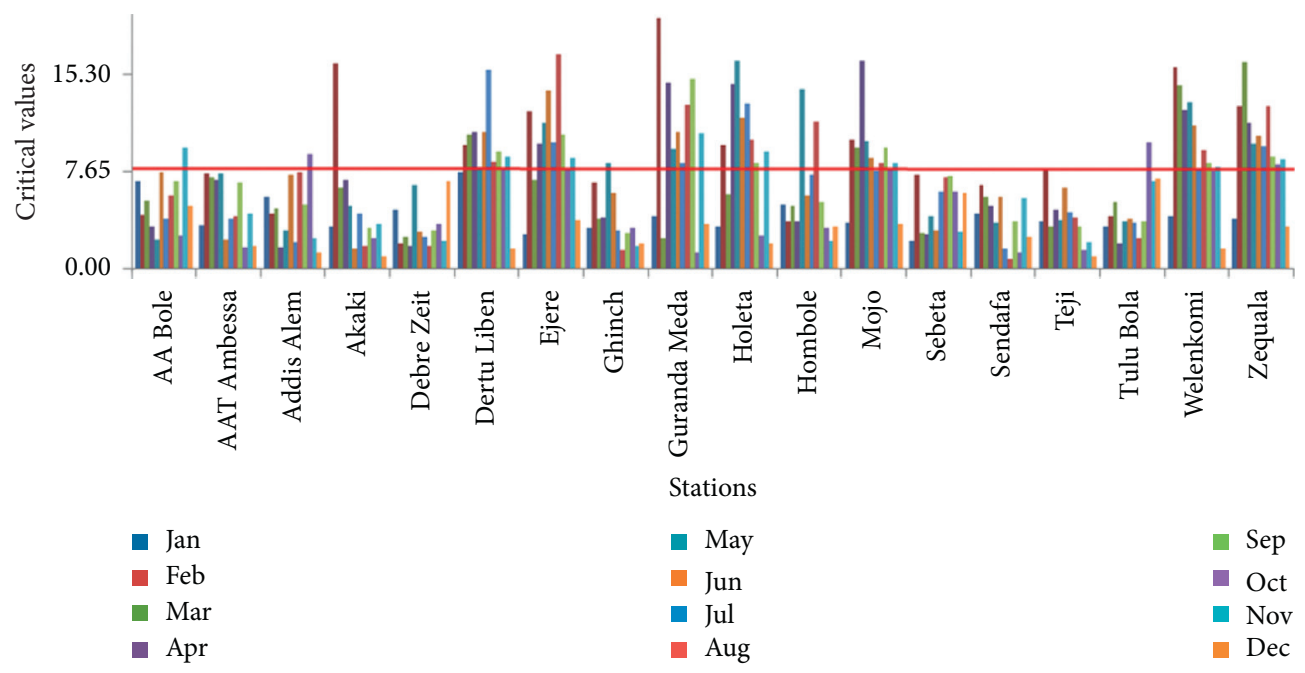

(a)

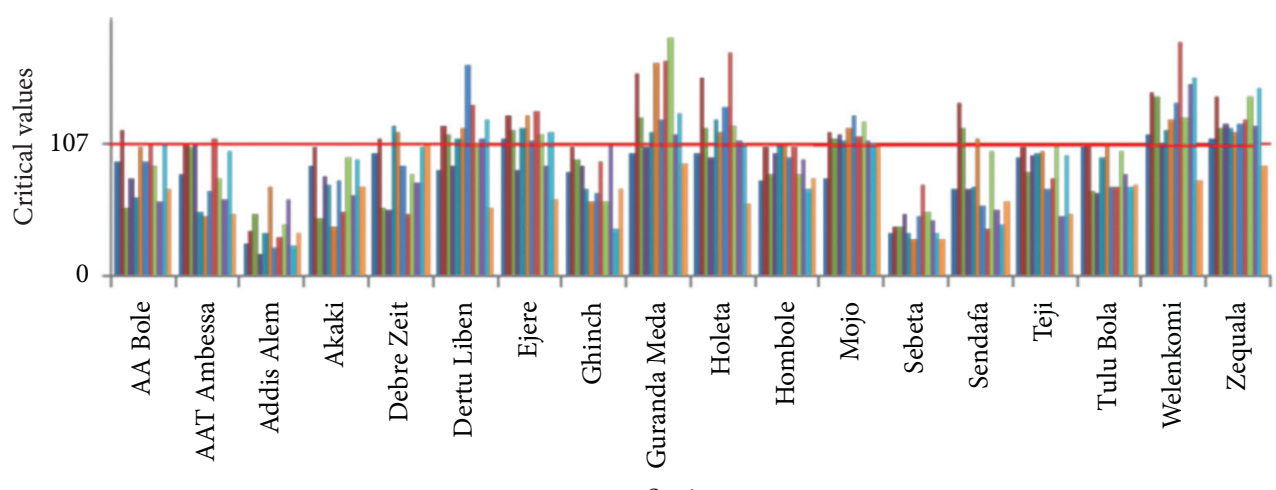

Stations
- Jan
- May
- Sep
- Feb
- Jun
- Oct
- Mar
- Jul
- Nov
- Apr

(b)

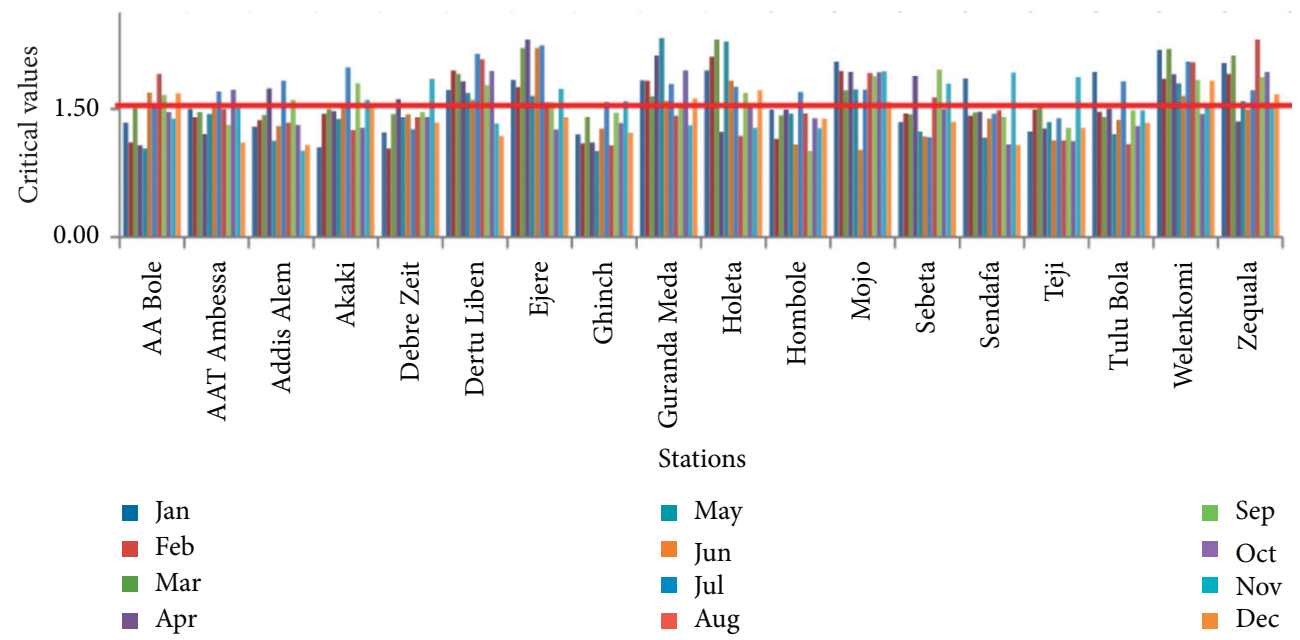

(c)

Figure 3: Continued. 


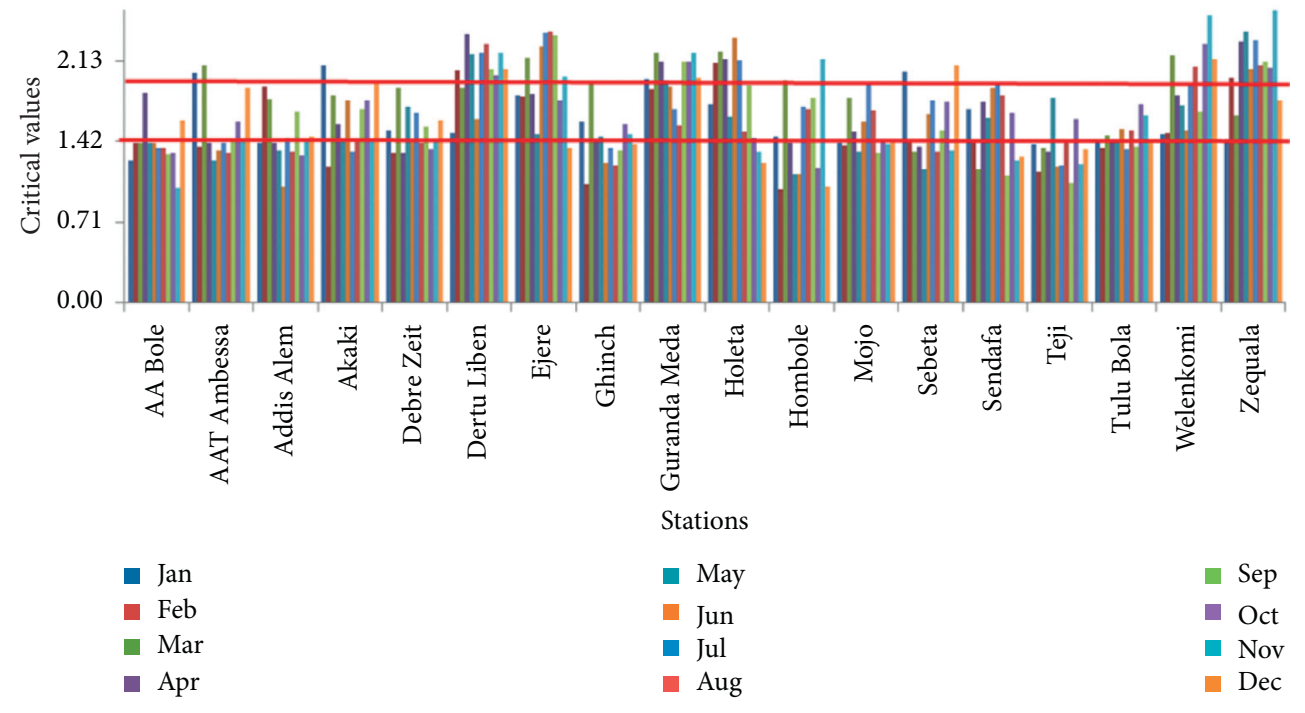

(d)

Figure 3: Results of (a) SNHT; (b) Pettitt's; (c) BR; and (d) VNR tests for monthly rainfall time series.

indicates that there are a break and rapid variation in the monthly means of the rainfall data series. Accordingly, the estimated test statistics for the data series higher than the threshold line at Addis Ababa Ambessa in months of January and March, at Akaki in January, at Dertu Liben in most months, except in January, March, and June, at Ejere in March, June, July, August, and September, at Guranda Meda in March, April, September, October, and November, at Holeta in February, March, April, June, and July, at Hombole in November, at Sebeta in January and December, at Welenkomi in March, August, October, November, and December, and at Zequala in most months, except in January, February, March, and December under the VNR test.

Based on the results of four homogeneity tests analyzed, 10 rainfall stations were categorized as homogeneous time series as the null hypothesis for the SNHT, Pettitt's test, BR, and VNR tests are not rejected at a $5 \%$ level of significance (Figure 3).

\subsection{Evaluation of Monthly Rainfall Time Series Homogeneity} Test Results. Based on the monthly rainfall data series analyses results obtained, using different tests were classified into three groups, as shown in Table 3. In this table, the characters (U: useful; D: doubtful; S: suspect) were used to classify homogeneity of monthly rainfall data series at each station. It can be seen that monthly rainfall time series inhomogeneity tests were detected at different stations. The monthly rainfall data belonging to Addis Ababa Bole, Addis Ababa Tikur Ambessa, Addis Alem, Akaki, Debre Zeit, Ghinch, Hombole, Sebeta, Sendafa, Teji, and Tulu Bolo stations showed homogeneity characteristic according to all tests. In December, except for Welenkomi and Zequala stations, all tests found homogeneous (labeled as useful). Since all homogeneity tests have identified the annual precipitation series of Dertu Liben, Ejere, Guranda Meda, Holeta, Mojo, Welenkomi, and Zequala as inhomogeneous, except for few months, the series has been labeled as suspect under all tests. So, any analysis of climate trends must be taken seriously, before further data analyses.

3.3. Annual Rainfall Time Series Homogeneity Tests. The summary of the four homogeneity test (Pettitt's test, SNHT, BRT, and VNR) results obtained for annual rainfall time series at different stations are shown in Table 4 . The alpha value 0.05 (95\% significance level) was used to identify homogeneity in the annual rainfall data series. The estimated test statistics for the annual rainfall data series higher than the alpha values were considered as homogeneous, whereas when the $P$ values were lower than the $5 \%$ significance level, data series were considered to be inhomogeneous. The results of the VNR test showed annual rainfall data series were found to be inhomogeneous for 5 stations, whereas the BR test showed inhomogeneities for 9 stations. The Pettitt's and $\mathrm{SNH}$ tests showed that the annual rainfall data series were inhomogeneous for 8 stations. The results of all tests showed the annual series of 10 rainfall stations were found homogeneous (labeled as "useful"). As it has been shown in the table, 7 stations were detected inhomogeneous under all tests. Accordingly, $58 \%$ of the rainfall stations were categorized as "useful," only $5 \%$ of the stations were categorized as "doubtful," and $37 \%$ of the rainfall stations were categorized as suspect (Figure 4). Thus, rainfall stations that fall under useful category or homogeneous data series were selected for trend analyses and further climate-based study.

3.4. Monthly Discharge Homogeneity Test Results. The results obtained using Pettitt's, SNHT, BRT, and VNR tests are given in Figure 5. Similar to the rainfall homogeneity test, the annual and monthly discharge time series of UASB were studied using four homogeneity tests. In this study, according to [40], the critical values used to determine the 
TABLE 3: Summary of monthly rainfall time series using different homogeneity tests.

\begin{tabular}{|c|c|c|c|c|c|c|c|c|c|c|c|c|}
\hline Station & Jan & Feb & Mar & Apr & May & Jun & Jul & Aug & Sept & Oct & Nov & Dec \\
\hline AA Bole & $\mathrm{U}$ & $\mathrm{U}$ & $\mathrm{U}$ & $\mathrm{U}$ & $\mathrm{U}$ & $\mathrm{U}$ & $\mathrm{U}$ & $\mathrm{U}$ & $\mathrm{U}$ & $\mathrm{U}$ & $\mathrm{U}$ & $\bar{U}$ \\
\hline AAT Ambessa & $\mathrm{U}$ & $\mathrm{U}$ & $\mathrm{U}$ & $\mathrm{U}$ & $\mathrm{U}$ & $\mathrm{U}$ & $\mathrm{U}$ & $\mathrm{U}$ & $\mathrm{U}$ & $\mathrm{U}$ & $\mathrm{U}$ & $\mathrm{U}$ \\
\hline Addis Alem & $\mathrm{U}$ & $\mathrm{U}$ & $\mathrm{U}$ & $\mathrm{U}$ & $\mathrm{U}$ & $\mathrm{U}$ & $\mathrm{U}$ & $\mathrm{U}$ & $\mathrm{U}$ & $\mathrm{U}$ & $\mathrm{U}$ & $\mathrm{U}$ \\
\hline Akaki & $\mathrm{U}$ & $\mathrm{U}$ & $\mathrm{U}$ & $\mathrm{U}$ & $\mathrm{U}$ & $\mathrm{U}$ & $\mathrm{U}$ & $\mathrm{U}$ & $\mathrm{U}$ & $\mathrm{U}$ & $\mathrm{U}$ & $\mathrm{U}$ \\
\hline Debre Zeit & $\mathrm{U}$ & $\mathrm{U}$ & $\mathrm{U}$ & $\mathrm{U}$ & $\mathrm{U}$ & $\mathrm{U}$ & $\mathrm{U}$ & $\mathrm{U}$ & $\mathrm{U}$ & $\mathrm{U}$ & $\mathrm{U}$ & $\mathrm{U}$ \\
\hline Dertu Liben & $\mathrm{U}$ & S & S & $S$ & S & S & S & S & $S$ & $\mathrm{~S}$ & S & $\mathrm{U}$ \\
\hline Ejere & $\mathrm{U}$ & S & S & S & S & S & S & S & S & $\mathrm{D}$ & S & $\mathrm{U}$ \\
\hline Ghinch & $\mathrm{U}$ & $\mathrm{U}$ & $\mathrm{U}$ & $\mathrm{U}$ & $\mathrm{U}$ & $\mathrm{U}$ & $\mathrm{U}$ & $\mathrm{U}$ & $\mathrm{U}$ & $\mathrm{U}$ & $\mathrm{U}$ & $\mathrm{U}$ \\
\hline Guranda Meda & $\mathrm{D}$ & S & S & S & S & S & $S$ & $S$ & S & $\mathrm{S}$ & S & $\mathrm{U}$ \\
\hline Holeta & $\mathrm{D}$ & S & $S$ & S & S & $S$ & $S$ & S & S & S & $\mathrm{D}$ & $\mathrm{U}$ \\
\hline Hombole & $\mathrm{U}$ & $\mathrm{U}$ & $\mathrm{U}$ & $\mathrm{U}$ & $\mathrm{U}$ & $\mathrm{U}$ & $\mathrm{U}$ & $\mathrm{U}$ & $\mathrm{U}$ & $\mathrm{U}$ & $\mathrm{U}$ & $\mathrm{U}$ \\
\hline Mojo & $\mathrm{U}$ & $S$ & $S$ & S & $\mathrm{U}$ & $S$ & $S$ & $S$ & $\mathrm{D}$ & $\mathrm{S}$ & S & $\mathrm{U}$ \\
\hline Sebeta & $\mathrm{U}$ & $\mathrm{U}$ & $\mathrm{U}$ & $\mathrm{U}$ & $\mathrm{U}$ & $\mathrm{U}$ & $\mathrm{U}$ & $\mathrm{U}$ & $\mathrm{U}$ & $\mathrm{U}$ & $\mathrm{U}$ & $\mathrm{U}$ \\
\hline Sendafa & $\mathrm{U}$ & $\mathrm{U}$ & $\mathrm{U}$ & $\mathrm{U}$ & $\mathrm{U}$ & $\mathrm{U}$ & $\mathrm{U}$ & $\mathrm{U}$ & $\mathrm{U}$ & $\mathrm{U}$ & $\mathrm{U}$ & $\mathrm{U}$ \\
\hline Teji & $\mathrm{U}$ & $\mathrm{U}$ & $\mathrm{U}$ & $\mathrm{U}$ & $\mathrm{U}$ & $\mathrm{U}$ & $\mathrm{U}$ & $\mathrm{U}$ & $\mathrm{U}$ & $\mathrm{U}$ & $\mathrm{U}$ & $\mathrm{U}$ \\
\hline Tulu Bolo & $\mathrm{U}$ & $\mathrm{U}$ & $\mathrm{U}$ & $\mathrm{U}$ & $\mathrm{U}$ & $\mathrm{U}$ & $\mathrm{U}$ & $\mathrm{U}$ & $\mathrm{U}$ & $\mathrm{U}$ & $\mathrm{U}$ & $\mathrm{U}$ \\
\hline Welenkomi & S & S & S & S & S & $S$ & $S$ & $S$ & $S$ & $S$ & $S$ & $S$ \\
\hline Zequela & S & S & S & S & S & S & S & S & S & $\mathrm{S}$ & S & S \\
\hline
\end{tabular}

U: useful; D: doubtful; S: suspect

TABLE 4: Rainfall results of four homogeneity tests at 95\% significance level.

\begin{tabular}{|c|c|c|c|c|c|c|}
\hline \multirow{2}{*}{ No } & \multirow{2}{*}{ Station } & \multicolumn{4}{|c|}{$P$-value of test statistics } & \multirow{2}{*}{ Remark } \\
\hline & & Pettitt's test & SHNT & BRT & VNR test & \\
\hline 1 & Addis Ababa Bole & 0.928 & 0.383 & 0.770 & 0.943 & Useful \\
\hline 2 & Addis Ababa T. Ambessa & 0.678 & 0.743 & 0.649 & 0.879 & Useful \\
\hline 3 & Addis Alem & 0.104 & 0.056 & 0.101 & 0.335 & Useful \\
\hline 4 & Akaki & 0.145 & 0.179 & 0.232 & 0.440 & Useful \\
\hline 5 & Debre Zeit & 0.437 & 0.947 & 0.730 & 0.945 & Useful \\
\hline 6 & Dertu Liben & 0.001 & 0.000 & 0.001 & 0.017 & Suspect \\
\hline 7 & Ejere & 0.008 & 0.023 & 0.014 & 0.037 & Suspect \\
\hline 8 & Ghinch & 0.049 & 0.244 & 0.107 & 0.157 & Useful \\
\hline 9 & Guranda Meda & 0.000 & 0.001 & 0.000 & 0.077 & Suspect \\
\hline 10 & Holeta & 0.015 & 0.043 & 0.017 & 0.465 & Suspect \\
\hline 11 & Hombole & 0.157 & 0.008 & 0.035 & 0.187 & Doubt \\
\hline 12 & Mojo & 0.003 & 0.006 & 0.001 & 0.062 & Suspect \\
\hline 13 & Sebeta & 0.46 & 0.146 & 0.005 & 0.750 & Useful \\
\hline 14 & Sendafa & 0.602 & 0.880 & 0.666 & 0.971 & Useful \\
\hline 15 & Teji & 0.669 & 0.857 & 0.821 & 0.750 & Useful \\
\hline 16 & Tulu Bolo & 0.542 & 0.547 & 0.437 & 0.091 & Useful \\
\hline 17 & Welenkomi & 0.002 & 0.008 & 0.000 & 0.034 & Suspect \\
\hline 18 & Zequela & 0.001 & 0.000 & 0.001 & 0.054 & Suspect \\
\hline
\end{tabular}

The bold numbers represent inhomogeneity in the corresponding stations and test statistics.

homogeneity of discharge data series for Pettitt's, SNHT, BRT, and VNR tests are $107,7.65,1.50$, and 1.42, respectively, at a $95 \%$ confidence level. All estimated statistics of the discharge data series less than those values were considered as homogeneous.

In SNHT, BRT, and VNR statistics estimated for the discharge time series at Melka Kunture, Teji, and Melka Sedi gauging stations were higher than the critical value in most of the months. It was found that in all test statistics, inhomogeneity was detected at different stations for the different months. Overall, inhomogeneity detected in monthly discharge data series of four months at Melka Kunture by all tests and four months at Teji and Melka Sedi by SNHT, BRT, and VNR tests. Compared to all tests, Pettitt's test found homogeneous data series in most of the stations, whereas Buishand's test detected inhomogeneity in most of the stations.

The summary results of homogeneity tests obtained for monthly discharge data series at each station are shown in Table 5. Similar to homogeneity tests in rainfall data series, the same characters ( $U, D$, and $S$ ) were used to classify homogeneity of monthly discharge data series at each station separately. Results suggest that discharge data series for most of the months were categorized as useful. The data series were found doubtful for the month of April at Melka Kunture and Teji , for July at Melka Sedi and Teji, for March, 


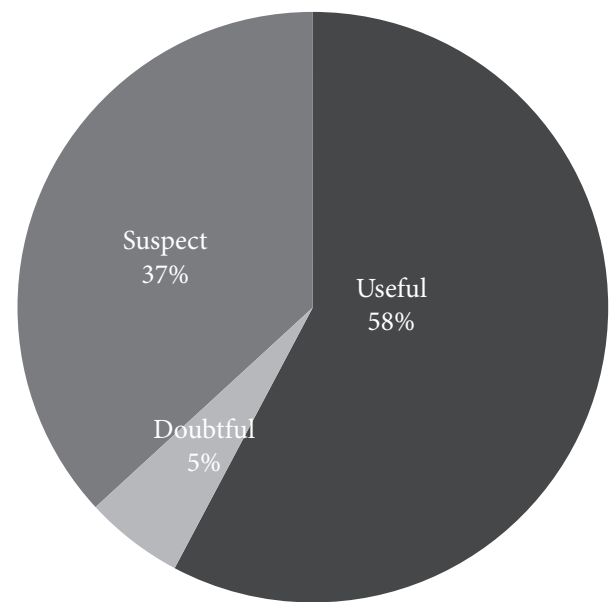

FIgURE 4: Categories of rainfall stations distribution (\%).

June, and August at Teji stations. On the other hand, the discharge data series were found suspect for most months at Melka Kunture, Teji, and Melka Sedi stations. Based on the results of all tests, 5 discharge gauging stations were categorized homogeneous time series as the null hypothesis for the SNHT, Pettitt's test, BRT, and VNR test are not rejected at $5 \%$ level of significance.

3.5. Annual Discharge Homogeneity Tests. The results obtained for annual discharge data series homogeneity tests at each station are shown in Table 6. The Pettitt's test and SNHT detect inhomogeneity of annual discharge data series at three stations, whereas BRT and VNR test at four stations. The results found that discharge data series for most of the stations were categorized as useful. In all tests, the annual data series at 5 out of 8 stations were found useful. The discharge time series is found suspect for the three stations since it failed from at least one of the four tests. Accordingly, $62 \%$ of the discharges gauging stations were categorized as "useful" and the remaining $38 \%$ of the gauging stations were categorized as suspect (Figure 6). Similarly, as done in rainfall stations, the homogeneous discharge gauging stations that fall under useful categories were selected for trend analysis.

The homogeneity tests revealed that the BRT was the most sensitive, and Pettitt's test was the least sensitive to detect inhomogeneity in annual data series. In the case of the monthly data series, the Pettitt's test was found most sensitive to detect inhomogeneity compared to other tests.

\subsection{Hydro Meteorological Trend Analysis}

3.6.1. Spatial-Temporal Trends in Annual and Seasonal Rainfall Data Series. Temporal trend analysis of annual and seasonal hydroclimatic time series was conducted using the Mann-Kendall (MK) and Sen's slope $(Q)$ tests of the selected homogeneous data. Summary of monthly, seasonal, and annual rainfall of all stations is shown in Table 7.

The mean annual rainfall totals of the UASB from 1980 to 2017 were found to be $1055.47 \mathrm{~mm}$. The recorded minimum and maximum average annual rainfall totals were 852.30 and $1215.36 \mathrm{~mm}$, respectively. The seasons of the study area were classified into three categories: Kiremt (JJAS), Bega (ONDJ), and Belg (FMAM) seasons. The contribution of seasonal rainfall (Kiremt, Bega, and Belg) to the total annual rainfall varied a lot over the study area. Kiremt is the main rainy season that mostly contributes to the total annual rainfall. Kiremt, Bega, and Belg seasons contribute about $71 \%, 6 \%$, and $23 \%$ to the annual rainfall totals, respectively (Table 7 ). The area received unimodal rainfall and Kiremt is the main rainy season and characterized by maximum rainfall. The present results show that the annual and seasonal patterns of rainfall reveal considerable variation across the study area.

In this study, MK and Sen's slope tests were applied to distinguish trends and their magnitude. Besides, trend $(Z$ values) and magnitude ( $Q$-value) have been computed. The summary of annual and seasonal rainfall trends analyzed using the MK test and Sen's slope estimator at the 90, 95, and $99 \%$ confidence levels is shown in Table 8 . The results showed that the annual mean rainfall had a statistically significant decreasing trend $(Z=-2.196$ and $Q=-19.81)$ in Bega season $(Z=-1.666$ and $Q=-4.38)$ at the Addis Alem station. Similarly, a significant decreasing trend was found in annual rainfall $(Z=-2.747$ and $Q=-12.38)$ in Belg season $(Z=-2.515$ and $Q=-6.03)$ at the Ghinch station. A statistically significant increasing trend was found in Bega season $(Z=2.379$ and $Q=2.31)$ at the Addis Ababa Bole station. In annual rainfall, a significant decreasing trends were observed at Akaki $(Z=-1.855$ and $Q=-5.60)$, and also significant decreasing trends were found in Belg season at Sebeta $(Z$ $=-1.818$ and $\mathrm{Q}=-3.15)$ and Sendefa $(\mathrm{Z}=-1.835$ and $\mathrm{Q}$ $=-3.81)$ stations. The MK results found a significant annual and seasonal rainfall trend which was observed at eight stations and most of the stations showed a negative trend, while in the remaining stations, no trend was detected.

The spatial trends mapped in annual and seasonal rainfall at 5\% significance level are shown in Figures $7(a)-$ $7(\mathrm{~h})$. The result reveals that in annual rainfall, significant negative trends were found in the northeast of the basin (Figure $7(\mathrm{a})$ ). The annual rainfall was decreasing only at some locations in the sub-basins at a rate of -5.6 to $-19.8 \mathrm{~mm}$ /year. In the Kiremt season, significant negative trends were detected in the northern part of the basin (Addis Alem and Sebeta stations) at $10 \%$ significance level (Figure 7(c)). In the Bega season, a significant positive trend was found in the Addis Ababa Bole station at 5\% significance level while a negative trend was found in Addis Alem at $10 \%$ significance level (Figure 7(e)). In the Belg season, significant negative trends were found in the Addis Ababa Tikur Ambessa and Ghinch at 5\% level of significance (Figure 7(g)).

The spatial interpolated maps of annual and seasonal rainfall are shown in Figures $8(\mathrm{a})-8(\mathrm{~d})$. The result reveals that in annual rainfall, higher values of rainfall are distributed in the northwestern part of the basin and lower values are distributed in the southeastern areas of the basin as shown in Figure 8(a). Mainly, Addis Ababa Bole, Addis Alem, Addis Ababa Tikur Ambessa, Ghinch, Sendefa, and 


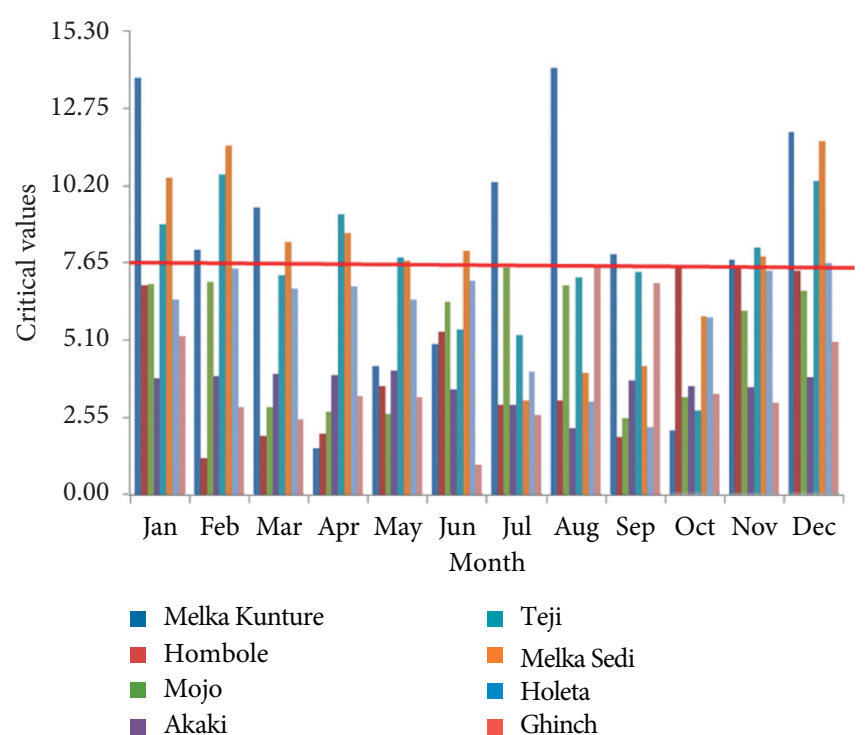

(a)

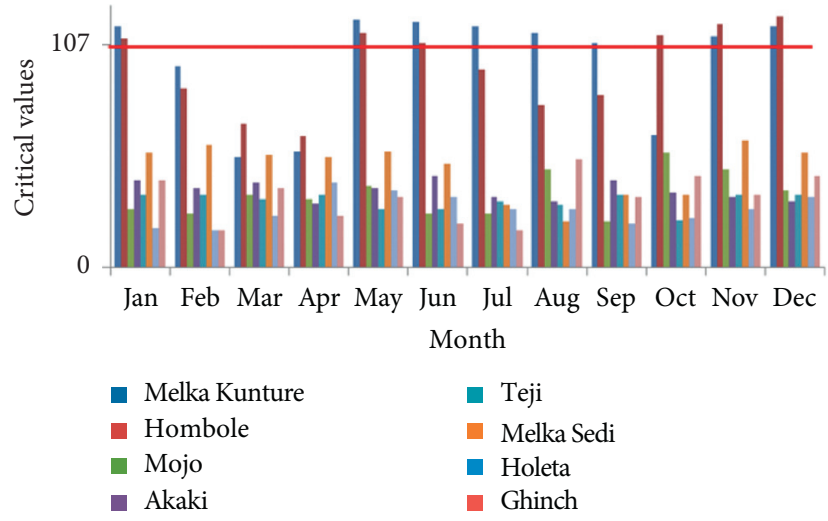

(c)

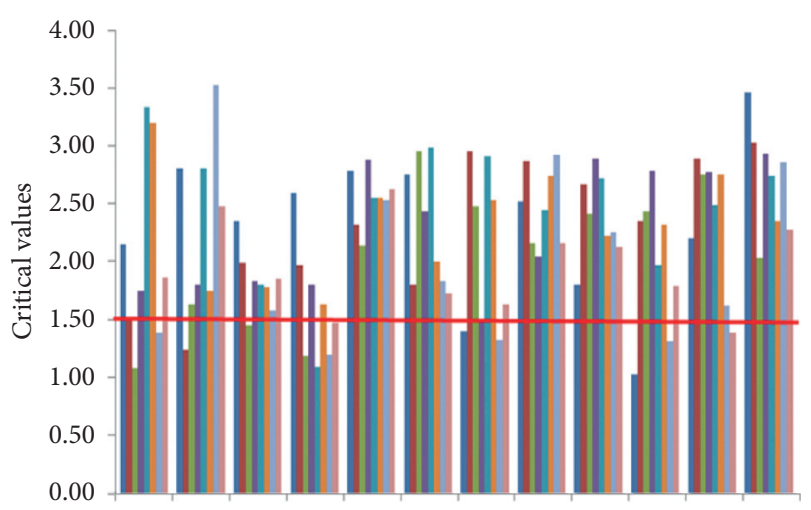

Jan Feb Mar Apr May Jun Jul Aug Sep Oct Nov Dec Month

$$
\begin{array}{ll}
\text { Melka Kunture } & \text { Teji } \\
\text { - Hombole } & \text { Melka Sedi } \\
\text { Mojo } & \text { Holeta } \\
\text { - Akaki } & \text { Ghinch }
\end{array}
$$

(b)

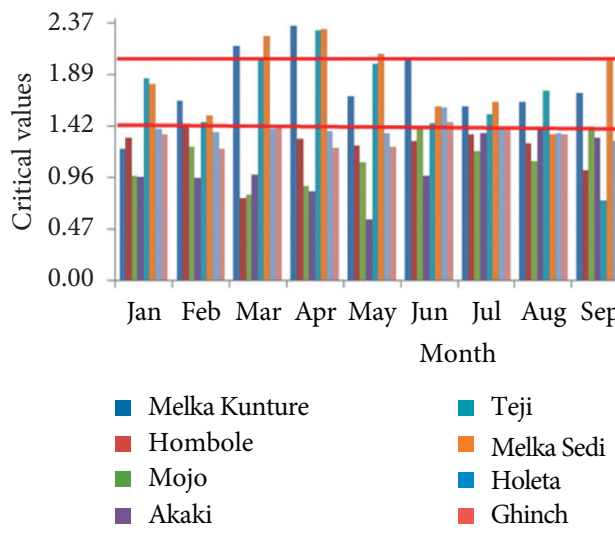

\begin{tabular}{|c|c|c|c|c|c|c|c|c|c|c|c|c|}
\hline Station & Jan & Feb & Mar & Apr & May & Jun & Jul & Aug & Sept & Oct & Nov & Dec \\
\hline Melka Kunture & $S$ & $\mathrm{~S}$ & $S$ & $\mathrm{D}$ & $S$ & $S$ & $\mathrm{~S}$ & S & S & $\mathrm{U}$ & $S$ & $S$ \\
\hline Hombole & $\mathrm{U}$ & $\mathrm{U}$ & $\mathrm{U}$ & $\mathrm{U}$ & $\mathrm{U}$ & $\mathrm{U}$ & $\mathrm{U}$ & $\mathrm{U}$ & $\mathrm{U}$ & $\mathrm{U}$ & $\mathrm{U}$ & $\mathrm{U}$ \\
\hline Mojo & $\mathrm{U}$ & $\mathrm{U}$ & $\mathrm{U}$ & $\mathrm{U}$ & $\mathrm{U}$ & $\mathrm{U}$ & $\mathrm{U}$ & $\mathrm{U}$ & $\mathrm{U}$ & $\mathrm{U}$ & $\mathrm{U}$ & $\mathrm{U}$ \\
\hline Akaki & $\mathrm{U}$ & $\mathrm{U}$ & $\mathrm{U}$ & $\mathrm{U}$ & $\mathrm{U}$ & $\mathrm{U}$ & $\mathrm{U}$ & $\mathrm{U}$ & $\mathrm{U}$ & $\mathrm{U}$ & $\mathrm{U}$ & $\mathrm{U}$ \\
\hline Teji & S & $S$ & $\mathrm{D}$ & $\mathrm{D}$ & S & $\mathrm{D}$ & $\mathrm{D}$ & $\mathrm{D}$ & $\mathrm{U}$ & $\mathrm{U}$ & S & $\mathrm{U}$ \\
\hline Melka Sedi & $\mathrm{U}$ & S & $S$ & S & $S$ & S & $\mathrm{D}$ & $\mathrm{U}$ & $\mathrm{D}$ & $\mathrm{D}$ & $S$ & $\mathrm{U}$ \\
\hline Holeta & $\mathrm{U}$ & $\mathrm{U}$ & $\mathrm{U}$ & $\mathrm{U}$ & $\mathrm{U}$ & $\mathrm{U}$ & $\mathrm{U}$ & $\mathrm{U}$ & $\mathrm{U}$ & $\mathrm{U}$ & $\mathrm{U}$ & $\mathrm{U}$ \\
\hline Ghinch & $\mathrm{U}$ & $\mathrm{U}$ & $\mathrm{U}$ & $\mathrm{U}$ & $\mathrm{U}$ & $\mathrm{U}$ & $\mathrm{U}$ & $\mathrm{U}$ & $\mathrm{U}$ & $\mathrm{U}$ & $\mathrm{U}$ & $\mathrm{U}$ \\
\hline
\end{tabular}

(d)

Figure 5: Result of (a) SNHT; (b) BR; (c) Pettitt's; and (d) VNR tests for monthly discharge data series.

TABLE 5: Summary of monthly discharge data series using different homogeneity tests.

U: useful; D: doubtful; S: suspect

Sebeta stations showed higher values of rainfall. The Kiremt season in the Upper Awash Basin showed wet condition in all stations. In dry seasons, commonly in Bega and Belg season, the area received moderately low rainfall range from 37 to $268 \mathrm{~mm}$. In the Bega season, higher values of rainfall are distributed in the northwestern (Addis Alem and Ghinch) and southern parts (Hombole) of the basin, whereas uniform distributions of rainfall were obtained in the eastern, western, and central parts of the basin. Lower rainfall values were perceived during "Bega" dry season in the ONDJ months; almost all parts of the basin received less than $110 \mathrm{~mm}$ as shown in Figure 8(c). Similarly, during the Belg season in the FMAM months, the spatial pattern revealed moderate rainfall distribution, which received up to $268 \mathrm{~mm}$ in the northwestern part and received more than $222 \mathrm{~mm}$ in the eastern part of the basin. 
TABLE 6: Annual discharge results of four homogeneity tests at $95 \%$ significance level.

\begin{tabular}{lcccccc}
\hline & \multicolumn{5}{c}{$P$ value of test statistics } \\
No & Station & $\begin{array}{c}\text { Pettitt's } \\
\text { test }\end{array}$ & SHNT & BRT & $\begin{array}{c}\text { VNR } \\
\text { test }\end{array}$ & Remark \\
\hline 1 & Melka & $\mathbf{0 . 0 0 3}$ & $\mathbf{0 . 0 0 3}$ & $\mathbf{0 . 0 0 1}$ & 0.073 & Suspect \\
2 & Kunture & & & & & \\
3 & Hombole & 0.813 & 0.592 & 0.776 & 0.891 & Useful \\
4 & Mojo & 0.352 & 0.215 & 0.295 & 0.570 & Useful \\
5 & Akaki & 0.753 & 0.493 & 0.328 & 0.075 & Useful \\
6 & Teji & $\mathbf{0 . 0 1 1}$ & $\mathbf{0 . 0 0 0 1}$ & $\mathbf{0 . 0 0 0}$ & $\mathbf{0 . 0 0 1}$ & Suspect \\
7 & Melka Sedi & $\mathbf{0 . 0 0 8}$ & $\mathbf{0 . 0 1 7}$ & $\mathbf{0 . 0 0 7}$ & $\mathbf{0 . 0 0 0}$ & Suspect \\
8 & Holeta & 0.350 & $\mathbf{0 . 0 3 4}$ & 0.257 & 0.290 & Useful \\
\hline
\end{tabular}

The bold numbers represent inhomogeneity in the corresponding stations and test statistics.

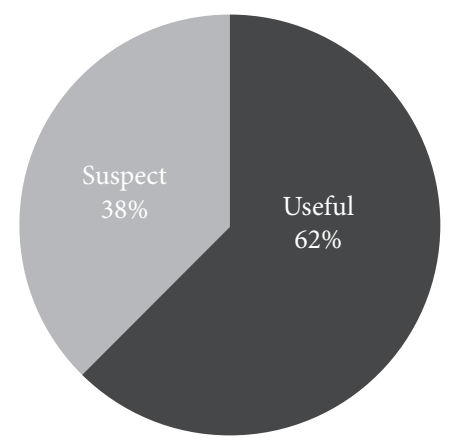

FIGURE 6: Categories of annual discharge stations distribution (\%).

3.6.2. Spatial-Temporal Trends in Annual and Seasonal Temperature Data Series. The annual and seasonal trends of mean temperatures were analyzed for the study area; using historical observed data from eight meteorological stations. The summary of annual and seasonal trend analysis of temperature at each station using the MK and Sen's slope tests is presented in Table 9. The MK test of annual mean temperature shows at almost all stations positive upward trend, except at one station. It shows that the upward temperature trends are more dominant. The annual temperature MK trend shows that statistically significant increasing trend was observed at Addis Ababa Bole $(Z=5.116$ and $Q=0.05)$, Addis Ababa Tikur Ambessa $(Z=3.604$ and $Q=0.03)$, Tulu Bolo $(Z=2.063$ and $Q=0.07)$, and Addis Alem $(Z=2.010$ and $Q=0.06)$, whereas decreasing trend was observed only at Akaki $(Z=-1.819$ and $Q=-0.06)$ in Kiremt season. The analyzed mean annual temperature of the eight stations shows statistically significant positive trends which were found in four series, whereas no trend was found in remaining stations. In accordance with the MK and Sen's slope tests, upward trends were found in seven-time series, and downward trends were found in one temperature time series.

Spatial patterns in the changes of annual and seasonal mean temperature over the UASB at 5\% level of confidence estimated by the MK test and Sen's slope are demonstrated in Figures 9(a)-9(g), only positive significant trends were observed in temperature stations over the UASB. As expected, most of the stations experienced increasing trend in annual and seasonal temperatures. However, no trend was observed at one station in both annual and seasonal temperature.

The spatial distribution of annual mean temperature trends exhibited that higher value in the highland areas of the basin mainly in the northern and western regions while the lower values were found in the central and southern portions of the basin. The annual mean temperatures were increasing in the Addis Ababa Bole, Addis Ababa Tikur Ambessa, Addis Alem, and Tulu Bolo at a rate of $0.03-0.07^{\circ} \mathrm{C} /$ year as shown in Figure 9(a). The MK trend test revealed seasonal and annual mean temperature at Addis Ababa Bole and Addis Ababa Tikur Ambessa stations which demonstrated statistically increasing trends at 0.01 significance level. However, the Kiremt temperature has experienced a significant decreasing trend at the Akaki station and no trends were obtained at Mojo and Holeta stations. The spatial distribution of Belg mean temperature in the UASB area increased from the east to the west, showing a clear difference in temperature between the two areas. The study reveals upward trends for three temperature stations in the northern part and one in the western part of the basin. However, there is no significant trend in some of seasonal and annual temperature time series (4 out of the 8 stations).

3.6.3. Spatial-Temporal Trends in Annual and Seasonal Discharge Data Series. The annual and seasonal discharge trend analysis summaries of five gauging stations are presented in Table 10. The MK results reveal that no trend was found in annual discharge of selected homogeneous gauging stations. Similarly, no trend was found in both Kiremt and Belg seasons. In the Bega season, only two stations revealed significance trend at 0.01 . Thus, MK trend and Sen's tests showed that statistically significant increasing trends were observed at Hombole $(\mathrm{Z}=3.527$ and $\mathrm{Q}=0.17)$ and Hombole $(\mathrm{Z}=3.127$ and $\mathrm{Q}=0.03)$ stations in Bega season.

The spatial trends in the annual and seasonal trends of discharge data series in UASB are shown in Figures 10(a)$10(\mathrm{~g})$ which reveals that no trend was found in annual, Kiremt, and Belg seasons in the sub-basin. The discharge value increases significantly in the drier ONDJ months in the Bega season at Hombole and Mojo stations at a rate of 0.03 to $0.17 \mathrm{~mm} /$ year. Positive significant trends were found in the southeastern parts of the UASB.

\section{Discussion}

Assessing the spatiotemporal variability of climate datasets is the first step to solve hydrological and water management problems. Below, we present a comprehensive discussion of hydroclimatic homogeneity tests and trends in hydroclimatic variables. Accordingly, the result of monthly and annual (rainfall and discharge) homogeneity tests and trend analysis for rainfall, temperature, and discharge data series are discussed in the following subsequent sections.

4.1. Hydroclimatic Homogeneity Tests. The importance of homogeneity test has been reported several times in many 
TABLE 7: Summary of monthly, seasonal, and annual rainfall ( $\mathrm{mm})$ of each station in the sub-basin.

\begin{tabular}{|c|c|c|c|c|c|c|c|c|c|c|c|c|}
\hline $\begin{array}{l}\text { Months } \\
\text { (season) }\end{array}$ & $\mathrm{AAB}$ & AATA & A. Alem & Akaki & $\begin{array}{c}\text { Debre } \\
\text { Zeit }\end{array}$ & Ghinch & Hombole & Sebeta & Sendafa & Teji & $\begin{array}{l}\text { Tulu } \\
\text { Bolo }\end{array}$ & $\begin{array}{l}\text { Mean RF } \\
(\mathrm{mm})\end{array}$ \\
\hline January & 17.30 & 13.13 & 15.84 & 10.45 & 9.98 & 24.93 & 53.82 & 15.575 & 14.92 & 11.48 & 12.66 & 18.20 \\
\hline February & 32.20 & 32.26 & 34.02 & 27.36 & 22.32 & 41.16 & 62.33 & 23.39 & 26.68 & 28.65 & 15.74 & 31.50 \\
\hline March & 67.60 & 63.01 & 69.71 & 55.35 & 55.32 & 72.48 & 83.61 & 64.04 & 50.30 & 52.22 & 51.54 & 62.30 \\
\hline April & 88.30 & 85.31 & 63.23 & 82.79 & 58.64 & 91.99 & 56.39 & 82.36 & 84.44 & 74.73 & 67.00 & 75.90 \\
\hline May & 77.10 & 80.15 & 79.21 & 64.73 & 59.43 & 90.73 & 54.02 & 82.01 & 55.53 & 73.14 & 102.03 & 74.40 \\
\hline June & 126.70 & 144.85 & 145.92 & 109.38 & 93.96 & 152.29 & 86.65 & 138.375 & 98.49 & 131.45 & 204.95 & 130.30 \\
\hline July & 240.70 & 266.03 & 260.53 & 234.29 & 204.10 & 227.40 & 189.94 & 266.75 & 327.59 & 214.75 & 275.86 & 246.20 \\
\hline August & 244.60 & 293.77 & 234.83 & 244.03 & 214.98 & 247.28 & 185.36 & 286.455 & 307.59 & 218.97 & 264.61 & 249.30 \\
\hline September & 127.5 & 185.02 & 129.98 & 117.09 & 103.40 & 142.01 & 84.90 & 134.81 & 102.65 & 101.73 & 111.54 & 121.90 \\
\hline October & 33.10 & 33.23 & 25.77 & 19.46 & 21.32 & 38.34 & 27.74 & 33.29 & 15.24 & 19.96 & 28.98 & 26.90 \\
\hline November & 8.60 & 8.95 & 23.82 & 5.62 & 5.00 & 11.11 & 9.97 & 10.51 & 4.59 & 6.71 & 12.13 & 9.70 \\
\hline December & 5.20 & 9.67 & 13.68 & 5.08 & 3.85 & 10.26 & 18.21 & 12.06 & 2.39 & 5.95 & 11.53 & 8.90 \\
\hline Kiremt (JJAS) & 739.55 & 889.67 & 771.27 & 704.79 & 616.44 & 768.98 & 546.85 & 826.39 & 836.32 & 666.90 & 856.95 & $747.65(71 \%)$ \\
\hline Bega (ONDJ) & 64.21 & 64.97 & 79.12 & 40.60 & 40.15 & 84.64 & 109.73 & 71.44 & 37.14 & 44.10 & 65.30 & $63.76(6 \%)$ \\
\hline Belg (FMAM) & 265.28 & 260.73 & 246.16 & 230.24 & 195.71 & 296.36 & 256.35 & 251.80 & 216.95 & 228.74 & 236.30 & $244.06(23 \%)$ \\
\hline $\begin{array}{l}\text { Annual RF } \\
\text { totals }\end{array}$ & 1069.05 & 1215.36 & 1096.54 & 975.63 & 852.30 & 1149.98 & 912.93 & 1149.63 & 1090.41 & 939.74 & 1158.56 & $\begin{array}{c}1055.47 \\
(100 \%)\end{array}$ \\
\hline
\end{tabular}

TABLE 8: Summary of $Z$ statistics and Sen's slope (Q) (mm/year) of the MK test for annual and seasonal rainfall of UASB.

\begin{tabular}{|c|c|c|c|c|c|c|c|c|}
\hline \multirow{2}{*}{ Station } & \multicolumn{2}{|c|}{ Annual } & \multicolumn{2}{|c|}{ Kiremt (JJAS) } & \multicolumn{2}{|c|}{ Bega (ONDJ) } & \multicolumn{2}{|c|}{ Belg (FMAM) } \\
\hline & $\mathrm{Mk}(\mathrm{zs})$ & Sen’s (Q) & $\mathrm{Mk}(\mathrm{zs})$ & Sen's (Q) & $\mathrm{Mk}(\mathrm{zs})$ & Sen's (Q) & $\mathrm{Mk}(\mathrm{zs})$ & Sen's (Q) \\
\hline AA Bole & -0.271 & -0.82 & 0.50 & 1.48 & 2.379 & $2.31^{* *}$ & -1.325 & -3.16 \\
\hline AA T. Ambessa & -0.470 & -2.32 & 1.189 & 3.2 & 0.679 & 0.58 & -2.124 & $-5.16^{* *}$ \\
\hline Addis Alem & -2.196 & $-19.81^{* *}$ & -1.893 & $-9.45^{*}$ & -1.666 & $-4.38^{*}$ & -1.060 & -6.7 \\
\hline Akaki & 1.855 & $-5.60^{*}$ & -0.249 & -0.71 & 0.285 & 0.24 & -1.213 & -2.479 \\
\hline Debre Zeit & 0.480 & 0.82 & 0.961 & 1.66 & 1.100 & 0.586 & -0.867 & -1.459 \\
\hline Ghinch & -2.747 & $-12.38^{* * *}$ & -1.248 & -5.25 & -0.178 & -0.275 & -2.515 & $-6.033^{* *}$ \\
\hline Hombole & -1.793 & $-9.49^{*}$ & -1.126 & -4.21 & 0.638 & 0.703 & -1.512 & -3.82 \\
\hline Sebeta & -1.200 & -4.06 & -1.784 & $-19.01^{*}$ & -0.875 & -1.659 & -0.779 & -4.819 \\
\hline Sendafa & -0.526 & -1.16 & 0.001 & 0.002 & 0.902 & 0.614 & -1.818 & $-3.15^{*}$ \\
\hline Teji & -0.560 & -1.48 & 0.951 & 2.12 & -0.527 & -0.18 & -1.835 & $-3.81^{*}$ \\
\hline Tulu Bolo & -1.239 & -5.97 & -0.476 & -2.71 & 0.054 & 0.007 & -0.585 & -1.057 \\
\hline
\end{tabular}

${ }^{* * *}$ Trend at $\alpha^{\prime}=0.01$ level. ${ }^{* *}$ Trend at $\alpha^{\prime}=0.05$ level. ${ }^{*}$ Trend at $\alpha^{\prime}=0.1$ level.

hydrological and climate studies [36, 38-40, 44]. In this study, the application of absolute homogeneity tests were applied to the data series of each station and results of each test were assessed at 95\% significance level and the inhomogeneities data series were identified for the trend analysis. The homogeneity tests showed that $11(58 \%)$ of the rainfall stations in UASB were detected as homogeneous series and the remaining 7 (37\%) stations are considered as inhomogeneous. Such study has been documented in previous works in different areas of the country. For example, in Ethiopia, homogeneity tests on selected rainfall data series were documented [69]. They mainly found that about $74 \%$ of the stations were found useful.

As far as discharge is concerned, 5 (63\%) of the discharge gauging stations were identified as homogeneity, whereas the remaining $3(37 \%)$ detected as inhomogeneous. In rainfall and discharge homogeneity tests, the Buishand's test found inhomogeneous compared to the remaining all tests.

In this study, sufficiently homogeneous rainfall and discharge stations that fall under useful category or homogeneous data series were selected for trend analyses and can be used for further hydrological and climate-based study.
4.2. Trends in Hydroclimatic Variables. In this study, spatialtemporal characteristics of annual and seasonal rainfall, temperature, and discharge in UASB were investigated from 1980 to 2017 . The above analysis showed that there were significant decreasing and increasing trends in annual and seasonal time series data. Thus, the presence of trends in hydroclimatic variables may probably be due to a change in the climate. In the past few years, several studies have been conducted globally on spatial and temporal trend analyses of hydroclimatic data using nonparametric and parametric methods $[16,23,25,43,60,70-78]$. They mainly found that spatial-temporal trends analyses are very important for impact assessment, water resource planning and management, and adaptation of planning for extreme events (floods and droughts) in the face of climate change.

In the Awash River Basin, trends in rainfall and temperature series are documented [23, 43, 48]. Generally, the findings of related studies match with the results obtained in this study using the MK test and Sen's slope. However, in their investigation, they did not carry out homogeneity and detailed seasonal based trends analyses and that will need another detailed research. In this study, homogeneity and 


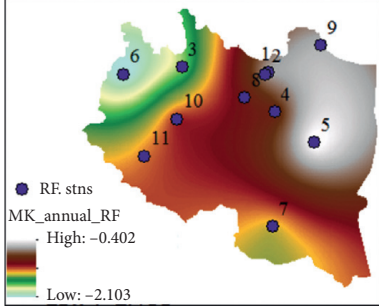

(a)

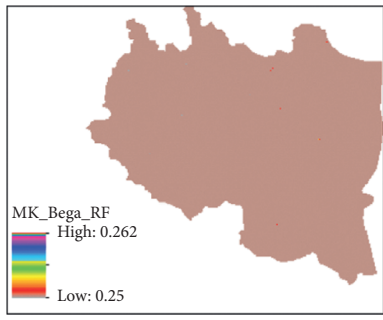

(e)

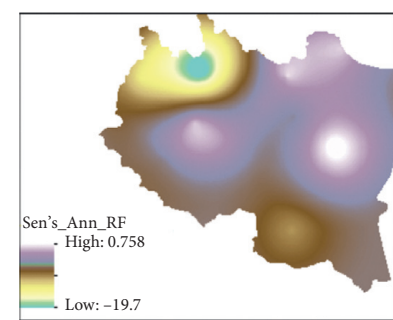

(b)

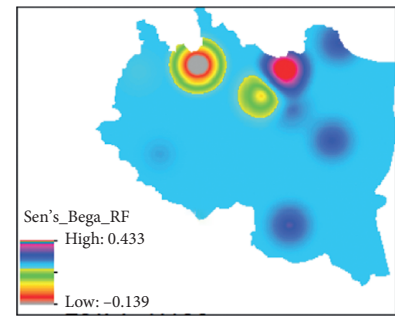

(f)

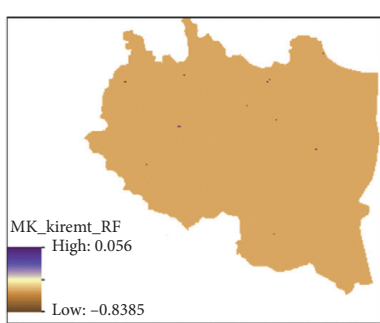

(c)

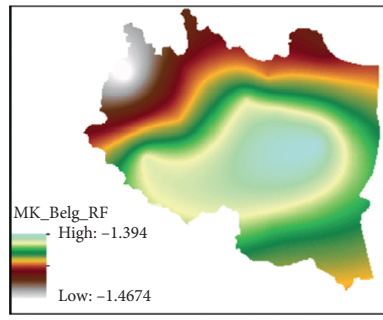

(g)

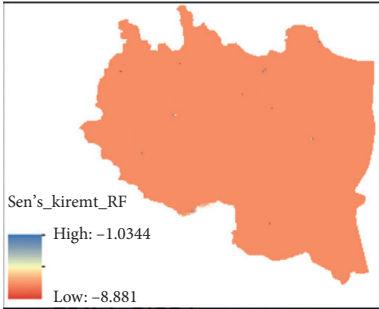

(d)

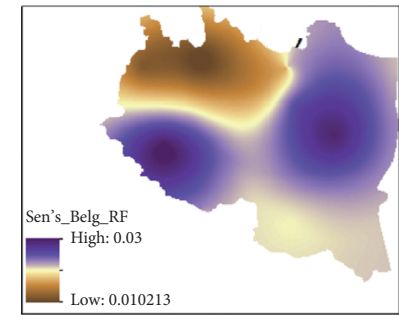

(h)

Figure 7: The spatial interpolated map of MK annual rainfall (a), Sen's annual rainfall (where $1=$ AA Bole, $2=$ AAT Ambessa, $3=$ Addis Alem, $4=$ Akaki, $5=$ Debre Zeit, $6=$ Ghinch, $7=$ Hombole, $8=$ Sebeta, $9=$ Sendafa, $10=$ Teji, and $11=$ Tulu Bola) (b), MK Kiremt (c), Sen's Kiremt (d), MK Bega (e), Sen's Bega (f), MK Belg (g), and Sen's Belg (h) in the Upper Awash Basin. Note: map of rainfall Sen's slope $Q$ units are in $\mathrm{mm} /$ year.

trend analyses at 8 discharge gauging stations, 18 rainfall stations, and 8 temperature stations over UASB were studied which would be useful for knowing details of the change in climatic conditions over a sub-basin. The results obtained show that the seasonal rainfall values were varied from season to season; for instance, the Kiremt rainfall varied from 546.85 to $889.67 \mathrm{~mm}$, Bega varied from 37.14 to $64.21 \mathrm{~mm}$, and Belg varied from 195.71 to $265.28 \mathrm{~mm}$ in the study area.

The results revealed that significant trends as well as no trend in annual and seasonal rainfall, discharge, and temperature data series were found during periods of 1980 to 2017 in the UASB. In this study, seasonal and annual time series trends were analyzed for the total of 44 rainfall series, 32 temperature series, and 20 discharge data series using MK and Sen's slope methods at 90, 95, and 99\% confidence levels. The results of the MK and Sen's slope tests showed that there were significantly negative and positive trends in the 12 time series of annual and seasonal rainfall; while significant positive trends were in the 2 time series of Bega discharge. Significant positive trends were detected in the 14 time series of annual and seasonal average temperatures. Statistically, significant decreasing annual rainfall trends were detected in the Akaki, Addis Alem, Hombole, and Ghinch stations. A significant decreasing annual and seasonal rainfall trend has been detected in some of stations, except increase at the Addis Ababa Bole station in Bega season. The seasonal and annual rainfall trends identified by MK and Sen's slope tests revealed that in Bega season, a significant negative trend was found at $10 \%$ level of significance in Addis Alem and Sendafa stations. In the Bega season, a significant positive trend was found in the Addis Ababa Bole station at 5\% significance level while a negative trend was found in the Addis Alem station at $10 \%$ significance level. In the Belg season, a significant negative trend was found in Addis Ababa Tikur Ambessa, Ghinch, Sendafa, and Teji stations. In agreement with the current finding, the result obtained supports the findings of [23] regarding the hydroclimatic trend and characterization. MK and Sen's slope tests revealed that more negative Zs values were detected in annual and seasonal rainfall. Thus, the negative downward rainfall trends are more dominant in the study area. Our research findings are consistent with several previous studies concerning the trend of rainfall and temperature variables [23, 43].

As far as temperature is concerned, the results of annual temperature trends identified by MK and Sen's slope tests showed that a significant positive trend was found at 0.05 levels of significance in Addis Ababa Bole, Addis Ababa Tikur Ambessa, Addis Alem, and Tulu Bolo stations. In the Kiremt, Bega, and Belg seasons, significant positive temperature trends were found at 0.1, 0.05, and 0.01 levels of significance in Addis Ababa Bole, Addis Ababa Tikur Ambessa, Debre Zeit, Holeta, and Tulu Bolo stations, while a significant negative trend was found at the Akaki station in Kiremt season. The trend in the annual temperature showed a statistically significant increase in most time series across the basin. The results of the study showed that there is a general increasing trend in temperature and a decreasing rainfall trend pattern observed across the stations and this is agreed with $[23,43,48]$ results. The statistical analysis of annual and seasonal hydroclimatic variables depicted a decreasing trend in the sub-basin. The observed trends analysis has an implication on agriculture production, particularly vulnerable areas, which are unable to mitigate the impacts of climate change [24]. According to the results of [23], the significant decreasing trends in annual rainfall and discharge were observed in the Awash River Basin. 


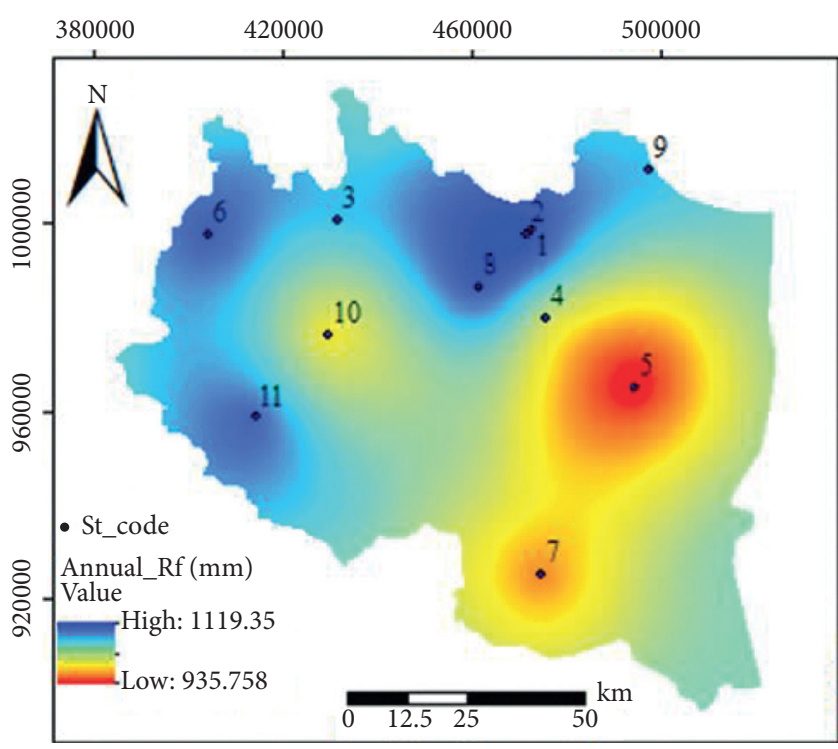

(a)

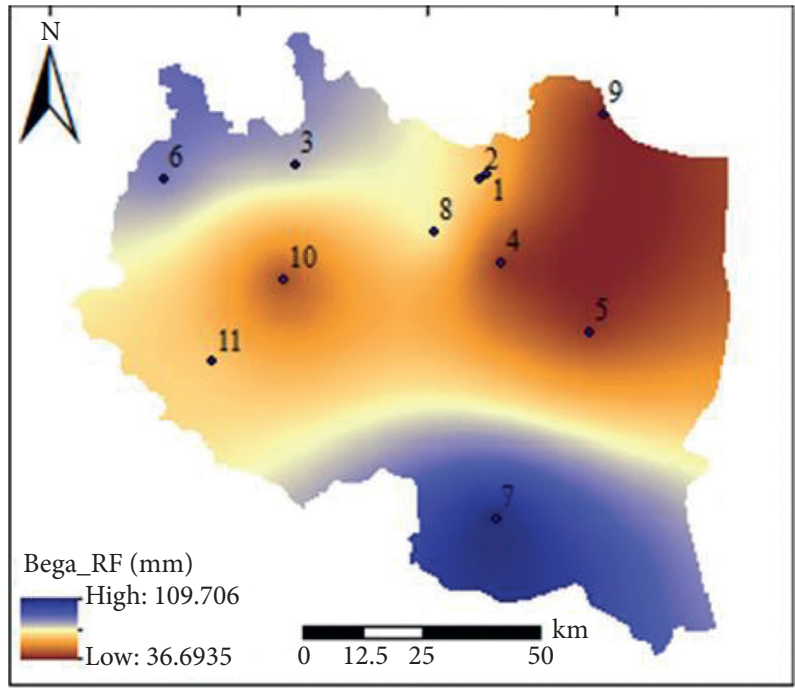

(c)

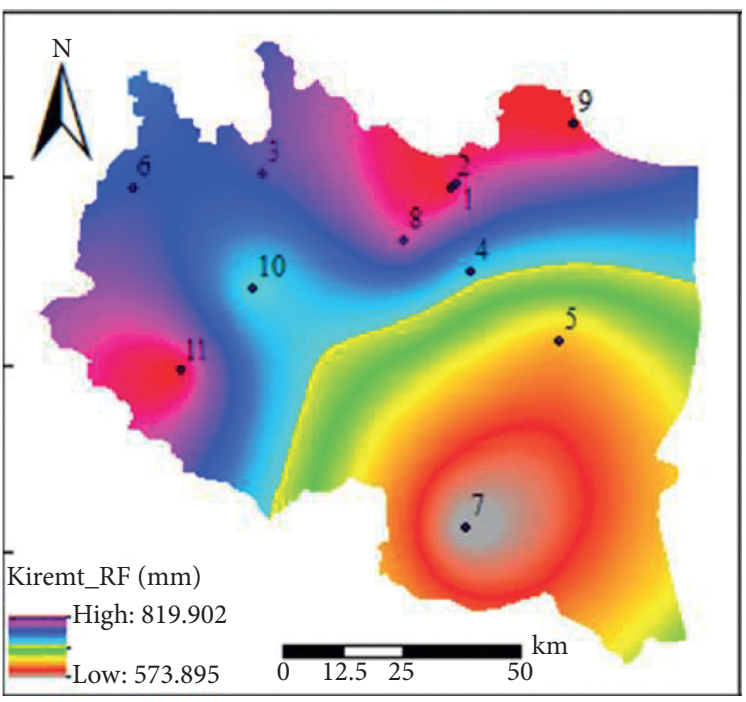

(b)

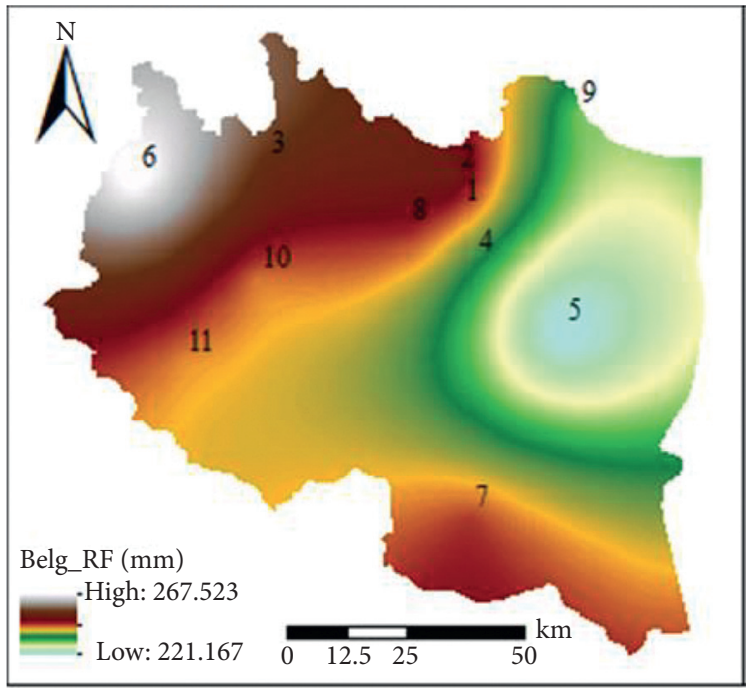

(d)

Figure 8: The spatial interpolated map of annual mean rainfall (a), Kiremt (b), Bega (c), and Belg (d) in the Upper Awash Basin. Note: $1=$ AA Bole. $2=$ AAT Ambessa. $3=$ Addis Alem. $4=$ Akaki. $5=$ Debre Zeit. $6=$ Ghinch. $7=$ Hombole. $8=$ Sebeta. $9=$ Sendafa. $10=$ Teji . $11=$ Tulu Bola.

TABLE 9: Summary of $Z$ statistics and Sen's slope $(Q)\left({ }^{\circ} \mathrm{C} /\right.$ year $)$ of MK test for annual and seasonal temperature of UASB.

\begin{tabular}{|c|c|c|c|c|c|c|c|c|}
\hline \multirow{2}{*}{ Station } & \multicolumn{2}{|c|}{ Annual } & \multicolumn{2}{|c|}{ Kiremt (JJAS) } & \multicolumn{2}{|c|}{ Bega (ONDJ) } & \multicolumn{2}{|c|}{ Belg (FMAM) } \\
\hline & $\mathrm{Mk}(\mathrm{zs})$ & Sen's (Q) & $\mathrm{Mk}(\mathrm{zs})$ & Sen's (Q) & $\mathrm{Mk}(\mathrm{zs})$ & Sen's (Q) & $\mathrm{Mk}(\mathrm{zs})$ & Sen's (Q) \\
\hline AA Bole & 5.116 & $0.05^{* * *}$ & 2.141 & $0.02^{* * *}$ & 2.124 & $0.02^{* *}$ & 5.608 & $0.07^{* * *}$ \\
\hline AA T. Ambessa & 3.604 & $0.03^{* * *}$ & 2.787 & $0.03^{* * *}$ & 2.798 & $0.04^{* * *}$ & 3.059 & $0.03^{* * *}$ \\
\hline Addis Alem & 2.010 & $0.06^{* *}$ & 1.363 & 0.04 & 1.590 & 0.09 & 1.666 & $0.11^{*}$ \\
\hline Akaki & -0.629 & -0.06 & -1.819 & $-0.06^{*}$ & -0.735 & -0.09 & -0.909 & -0.05 \\
\hline Debre Zeit & 1.343 & 0.02 & 1.241 & 0.02 & 0.204 & 0.002 & 2.176 & $0.03^{* *}$ \\
\hline Holeta & 0.852 & 0.01 & -0.201 & -0.003 & 1.905 & $0.02^{*}$ & 0.263 & 0.003 \\
\hline Mojo & 0.518 & 0.01 & 0.978 & 0.02 & 1.586 & 0.02 & -0.385 & -0.005 \\
\hline Tulu Bolo & 2.063 & $0.07^{* *}$ & 1.819 & $0.06^{*}$ & 1.106 & 0.03 & 4.240 & $0.09^{* * *}$ \\
\hline
\end{tabular}

${ }^{* * *}$ Trend at $\alpha^{\prime}=0.01$ level. ${ }^{* *}$ Trend at $\alpha^{\prime}=0.05$ level. ${ }^{*}$ Trend at $\alpha^{\prime}=0.1$ level. 


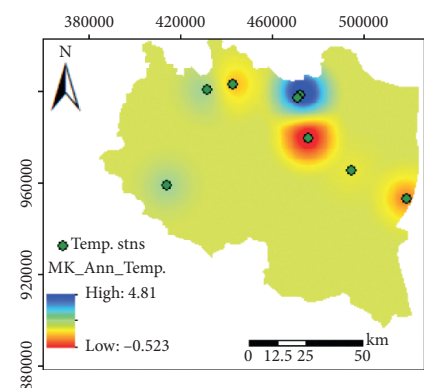

(a)

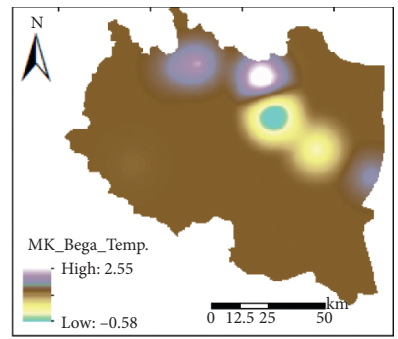

(e)

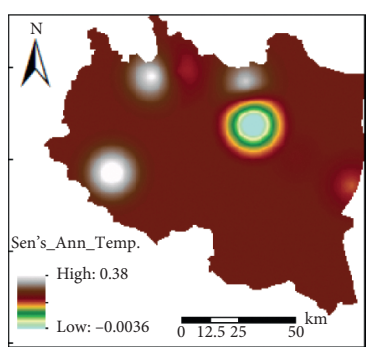

(b)

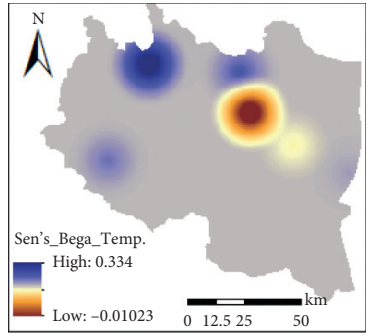

(f)

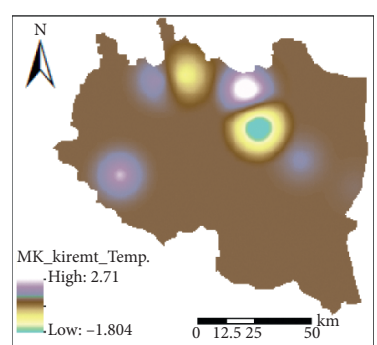

(c)

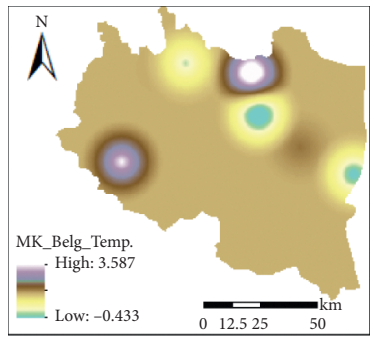

(g)

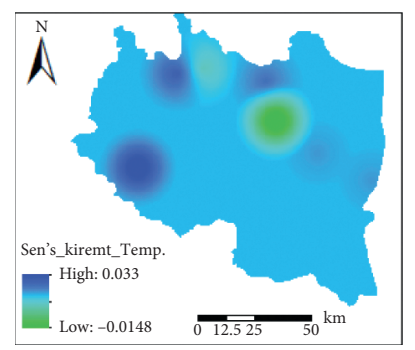

(d)

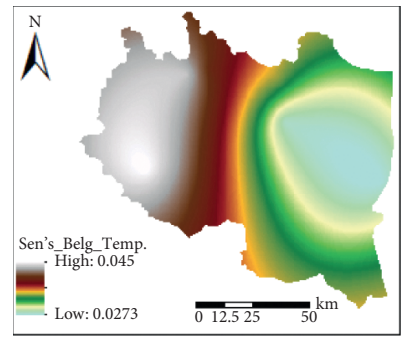

(h)

Figure 9: The spatial interpolated map of MK annual mean temperature (a), Sen's annual mean temperature (b), MK Kiremt (c), Sen's Kiremt (d), MK Bega (e), Sen's Bega (f), MK Belg (g), and Sen's Belg (h) in the Upper Awash Basin. Note: map of temperature Sen's slope $Q$ units are in ${ }^{\circ} \mathrm{C} /$ year.

TABle 10: The Sen's slope $(Q)$ (mm/year) and $Z$ statistics of the MK test for seasonal and annual discharge of UASB.

\begin{tabular}{lcccccccc}
\hline \multirow{2}{*}{ Station } & \multicolumn{2}{c}{ Annual } & \multicolumn{2}{c}{ Kiremt (JJAS) } & \multicolumn{2}{c}{ Bega (ONDJ) } & \multicolumn{2}{c}{ Belg (FMAM) } \\
& Mk (zs) & Sen's (Q) & Mk (zs) & Sen's (Q) & Mk (zs) & Sen's (Q) & Mk (zs) & Sen's (Q) \\
\hline Hombole & 0.258 & 0.05 & -0.122 & -0.14 & 3.527 & $0.17^{* * *}$ & 0.612 \\
Holeta & 0.407 & 0.02 & -0.038 & -0.01 & 0.451 & 0.01 & 0.03 \\
Ghinch & -1.326 & -0.04 & -0.370 & -0.04 & -0.999 & -0.01 & -0.549 \\
Akaki & 0.315 & 0.14 & 1.143 & 0.35 & 0.225 & 0.03 & 0.315 \\
Mojo & 1.488 & -0.15 & -1.305 & -0.48 & 3.127 & $0.03^{* * *}$ & 0.497 \\
\hline
\end{tabular}

${ }^{* * *}$ Trend at $\alpha^{\prime}=0.01$ level.

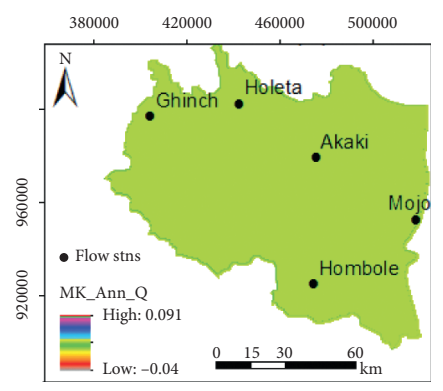

(a)

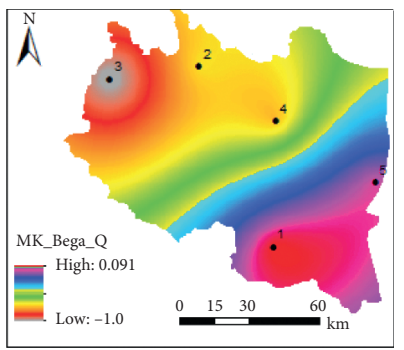

(e)

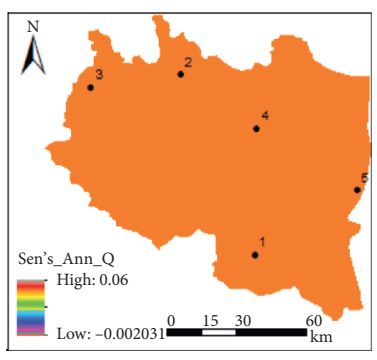

(b)

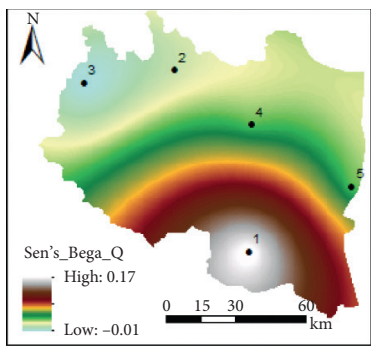

(f)

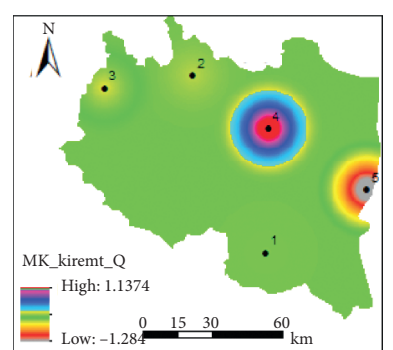

(c)

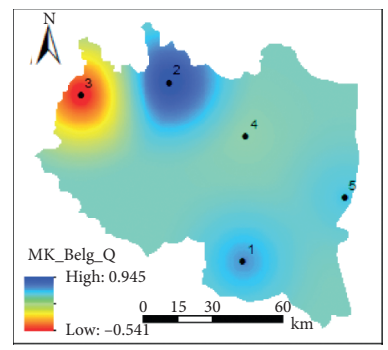

(g)

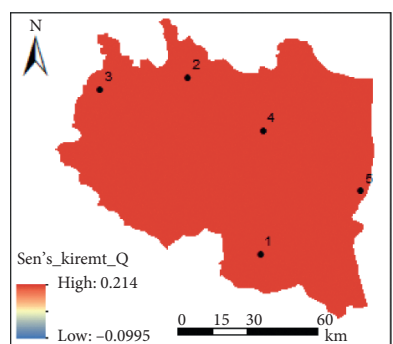

(d)

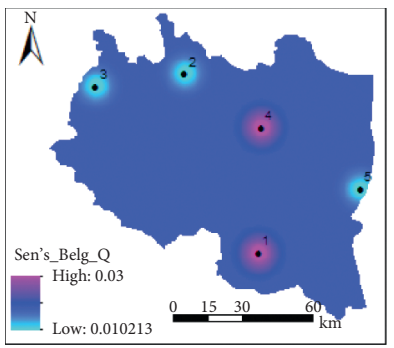

(h)

FiguRE 10: The spatial interpolated map of MK annual mean discharge (a), Sen's annual mean discharge (b), MK Kiremt (c), Sen's Kiremt (d), MK Bega (e), Sen's Bega (f), MK Belg (g), and Sen's Belg (h) in the Upper Awash Basin. Note: map of discharge Sen's slope $Q$ units are in $\mathrm{mm} /$ year. 
The Mann-Kendall (MK) trend test based on the annual and seasonal discharge series revealed that most of the meteorological stations have statistically no trend at a $5 \%$ significance level. The results of seasonal and annual discharge trends identified by MK and Sen's slope tests revealed that in the Bega season, a significant positive trend was found at $1 \%$ levels of significance in Mojo and Hombole gauging stations. The results showed that the seasonal discharge of UASB had a significant tendency to increase at two gauging stations only. Besides, the annual and seasonal detected negative upwards of discharge percentages were about $40 \%, 80 \%, 20 \%$, and $20 \%$ of the stations in annual, Kiremt, Bega, and Belg seasons, respectively. This shows the positive upward discharge trends were more dominant in the study area. Similarly, the study reported by [23, 43] found that rainfall and discharge in the Awash River Basin showed an increasing trend. In Holeta, Ghinch, and Akaki stations, no significant trends were seen for the annual and seasonal streamflows. Moreover, Mann-Kendall and Sen's tests did not consider the assumption of autocorrelation, test number, and nonnormality in the time series analyses, which affects the significance of trends. Thus, to reduce such uncertainties, data series autocorrelation analyses $[79,80]$ and evaluates the long-term persistence $[81,82]$ of data analyses are very crucial and recommendable for the significance of trend analyses.

\section{Conclusions}

Data availability and accuracy are the most important factors in climate and hydrological researches. One way of assessing reliability of a climate data series is to compare it with surrounding gauged stations, which remains to be the driving force behind all tests of relative homogeneity. Here, we presented the application of different statistical tests to analyse homogeneity and trends in rainfall, temperature, and discharge in the Upper Awash sub-basin (UASB) in Ethiopia for a period of nearly four decades, 1980 through 2017. The homogeneity of the annual and monthly rainfall and discharge data series of UASB was studied using four statistical tests; Pettitt's test [34], SNHT [52], BRT [32], and VNR [35]. The rainfall and discharge data series were analyzed at a 0.05 significance level for each homogeneity test separately. Annual and seasonal trend analysis for discharge, rainfall, and temperature was done at each station. To meet the outlined objective of this study, the homogeneity tests, the Mann-Kendall test, and Sen's slope test estimator were employed.

In order to provide seasonal comparison of changes in hydroclimatic variables, the analyses were performed for three seasons, Kiremt, Bega, and Belg. The homogeneity tests revealed that most of the monthly and annual (rainfall and discharge) stations were classified as useful (homogeneous). The results also indicated that both monthly and annual hydroclimatic homogeneity tests are almost similar. Since the annual rainfall and discharge time series are comparatively more homogeneous related to the monthly time series, the data can be used for trend analyses and hydroclimatic studies in the UASB. The results of MK and Sen's slope tests showed a statistically significant decreasing annual rainfall trends for some of the stations, while a significantly increasing trend in annual rainfall was observed only at one station. The majority of rainfall stations exhibited a decreasing trend in the mean annual rainfall for Kiremt and Belg seasons. On the other hand, one observed station showed an increasing trend for the Bega season. Most of the stations exhibited no trend in annual and seasonal time series of rainfall, temperature, and discharge. The temporal variations of seasonal and annual discharge data series are not statistically significant for most of gauging stations. The results showed that most of the UASB have not experienced any trend in annual and seasonal discharge (except significant increasing trends which were found at Hombole and Mojo stations in the Bega season). The study found that the downward trend is dominant in precipitation, while upward trends were dominant in temperature and discharge.

In general, the trends exhibited higher variability of rainfall on the annual and Belg season compared to the Kiremt and Bega seasons. The remarkable characteristics of the UASB are that the northwestern areas in the upper parts receive a larger amount of mean annual rainfall while the lower magnitude of annual rainfall was observed compared to the southeastern parts of the basin. Mainly at the higher elevation areas, the spatial pattern of annual and seasonal rainfall demonstrated downward trends.

Based on the previous results and discussion, it can be concluded that decreasing and increasing levels of rainfall, discharge, and temperature across all stations showed the change in hydroclimatic variables. This would suggest any climate and hydrological studies to test the homogeneity and trends of a given dataset before applying for any future impact assessment. Overall, this finding provides useful information for hydroclimatologists and managers for better decision making regarding future agricultural and water resources management in the face of climate change.

\section{Data Availability}

The data generated during the study are available within the article.

\section{Conflicts of Interest}

The authors declare no conflicts of interest.

\section{Authors' Contributions}

Mekonnen H. Daba and Songcai You were responsible for conceptualization; Mekonnen H. Daba and Songcai You were involved in the methodology; Songcai You supervised the study; Mekonnen H. Daba was responsible for writing the original draft; Mekonnen H. Daba, Songcai You, and Gebiaw T. Ayele were responsible for writing, reviewing, and 
editing. All authors have read and agreed to the published version of the manuscript.

\section{Acknowledgments}

The authors acknowledge the Ministry of Science and Technology (MOST) of China for the financial support. The authors express their gratitude to the Ethiopian Ministry of Water Resources and National Meteorological Services Agency for providing them hydrological and meteorological data. This work was supported by the Ministry of Science and Technology (MOST) of China (grant no. 2017YFD0300400).

\section{References}

[1] A. Hessler, "Earth's earliest climate," Nature Education Knowledge, vol. 3, no. 10, p. 24, 2011.

[2] IPCC, Climate Change 2014: Synthesis Report. Contribution of Working Groups I, II and III to the Fifth Assessment Report of the Intergovernmental Panel on Climate Change, IPCC, Geneva, Switzerland, 2014.

[3] O. Hoegh-Guldberg, Impacts of $1.5 \mathrm{C}$ global warming on natural and human systems. Global Warming of $1.5^{\circ} \mathrm{C}$. An IPCC Special Report, Intergovernmental Panel on Climate Change, Geneva, Switzerland, 2018.

[4] P. K. Thornton, P. J. Ericksen, M. Herrero, and A. J. Challinor, "Climate variability and vulnerability to climate change: a review," Global Change Biology, vol. 20, no. 11, pp. 3313-3328, 2014.

[5] T. F. Stocker, Climate Change 2013: The Physical Science Basis. Contribution of Working Group I to the Fifth Assessment Report of the Intergovernmental Panel on Climate Change, Cambridge University Press, Cambridge, UK, 2013.

[6] S. Ali, Y. Liu, M. Ishaq et al., "Climate change and its impact on the yield of major food crops: evidence from Pakistan," Foods, vol. 6, no. 6, p. 39, 2017.

[7] J. Ochieng, L. Kirimi, and M. Mathenge, "Effects of climate variability and change on agricultural production: the case of small scale farmers in Kenya," NJAS-Wageningen Journal of Life Sciences, vol. 77, pp. 71-78, 2016.

[8] F. Zhai and J. Zhuang, "Agricultural impact of climate change: a general equilibrium analysis with special reference to Southeast Asia," Climate Change in Asia and the Pacific: How Can Countries Adapt, pp. 17-35, SAGE Publications India, Chennai, India, 2012.

[9] E. Vogel, "The effects of climate extremes on global agricultural yields," Environmental Research Letters, vol. 14, no. 5, Article ID 054010, 2019.

[10] S. H. Gebrechorkos, S. Hülsmann, and C. Bernhofer, "Longterm trends in rainfall and temperature using high-resolution climate datasets in East Africa," Scientific Reports, vol. 9, no. 1, pp. 1-9, 2019.

[11] N. Karmeshu, "Trend detection in annual temperature \& precipitation using the Mann Kendall test-a case study to assess climate change on select states in the northeastern United States," in Proceedings of the 2012 International Sustainable Buildings Symposium, Fort Worth, TX, USA, 2012.

[12] B. Praveen, "Analyzing trend and forecasting of rainfall changes in India using non-parametrical and machine learning approaches," Scientific Reports, vol. 10, no. 1, pp. 1-21, 2020.
[13] S. K. Amare, K. Zebene, and N. E. Agizew, "Evaluating water quality of Awash river using water quality index," International Journal of Water Resources and Environmental Engineering, vol. 9, no. 11, pp. 243-253, 2017.

[14] A. Asfaw, B. Simane, A. Hassen, and A. Bantider, "Variability and time series trend analysis of rainfall and temperature in northcentral Ethiopia: a case study in Woleka sub-basin," Weather and Climate Extremes, vol. 19, pp. 29-41, 2018.

[15] M. Gedefaw, D. Yan, H. Wang et al., "Innovative trend analysis of annual and seasonal rainfall variability in Amhara regional state, Ethiopia," Atmosphere, vol. 9, no. 9, p. 326, 2018.

[16] R. Mahmood, S. Jia, and W. Zhu, "Analysis of climate variability, trends, and prediction in the most active parts of the Lake Chad basin, Africa," Scientific Reports, vol. 9, no. 1, p. $6317,2019$.

[17] A. Worqlul, Y. T. Dile, E. Ayana, J. Jeong, A. Adem, and T. Gerik, "Impact of climate change on streamflow hydrology in headwater catchments of the upper Blue Nile basin, Ethiopia," Water, vol. 10, no. 2, p. 120, 2018.

[18] M. H. Daba, "Modelling the impacts of climate change on surface runoff in Finchaa sub-basin, Ethiopia," Journal of the Science of Food and Agriculture, vol. 2, pp. 14-29, 2018.

[19] J. J. Huang, N. Zhang, G. Choi, E. A. McBean, and Q. Zhang, "Spatiotemporal patterns and trends of precipitation and their correlations with related meteorological factors by two sets of reanalysis data in China," Hydrology and Earth System Sciences Discussions, pp. 1-35, 2018.

[20] B. Dorjsuren, D. Yan, H. Wang et al., "Observed trends of climate and river discharge in Mongolia's Selenga sub-basin of the lake Baikal basin," Water, vol. 10, no. 10, p. 1436, 2018.

[21] N. Folton, "A 50-year analysis of hydrological trends and processes in a Mediterranean catchment," Hydrology and Earth System Sciences Discussions, pp. 1-28, 2018.

[22] M. Daba, "Agro climatic characterization in the selected woredas of western Oromia, Ethiopia," Journal of Earth Science and Climatic Change, vol. 9, no. 455, p. 2, 2018.

[23] M. T. Tadese, L. Kumar, R. Koech, and B. Zemadim, "Hydroclimatic variability: a characterisation and trend study of the Awash river basin, Ethiopia," Hydrology, vol. 6, no. 2, p. 35, 2019.

[24] M. Gedefaw, D. Yan, H. Wang, T. Qin, and K. Wang, "Analysis of the recent trends of two climate parameters over two eco-regions of Ethiopia," Water, vol. 11, no. 1, p. 161, 2019.

[25] H. M. Meena, D. Machiwal, P. Santra, P. C. Moharana, and D. V. Singh, "Trends and homogeneity of monthly, seasonal, and annual rainfall over arid region of Rajasthan, India," Theoretical and Applied Climatology, vol. 136, no. 3-4, pp. 795-811, 2018.

[26] M. L. Tan, V. P. Chua, C. Li, and K. Brindha, "Spatiotemporal analysis of hydro-meteorological drought in the Johor river basin, Malaysia," Theoretical and Applied Climatology, vol. 135, no. 3-4, pp. 825-837, 2019.

[27] R. S. V. Teegavarapu, "Changes and trends in precipitation extremes and characteristics," Trends and Changes in Hydroclimatic Variables, Elsevier, Amsterdam, Netherlands, 2019.

[28] G. Worku, E. Teferi, A. Bantider, and Y. T. Dile, "Observed changes in extremes of daily rainfall and temperature in Jemma sub-basin, upper Blue Nile basin, Ethiopia," Theoretical and Applied Climatology, vol. 135, no. 3-4, pp. 839-854, 2019. 
[29] S. Hänsel, D. M. Medeiros, J. Matschullat, R. A. Petta, and I. de Mendonça Silva, "Assessing homogeneity and climate variability of temperature and precipitation series in the capitals of north-eastern Brazil," Frontiers in Earth Science, vol. 4 , p. 29, 2016.

[30] N. H. Ahmad and S. M. Deni, "Homogeneity test on daily rainfall series for Malaysia," Matematika, vol. 29, p. 10, 2013.

[31] H. Alexandersson and A. Moberg, "Homogenization of Swedish temperature data. Part I: homogeneity test for linear trends," International Journal of Climatology, vol. 17, p. 10, 1997.

[32] T. A. Buishand, "Some methods for testing the homogeneity of rainfall records," Journal of Hydrology, vol. 58, p. 17, 1982.

[33] N. Mizukami and M. B. Smith, "Analysis of inconsistencies in multi-year gridded quantitative precipitation estimate over complex terrain and its impact on hydrologic modeling," Journal of Hydrology, vol. 428-429, pp. 129-141, 2012.

[34] A. N. Pettitt, "A non-parametric approach to the changepoint problem," Applied Statistics, vol. 28, no. 2, 1979.

[35] J. von Neumann, "The mean square successive difference," Annals of Mathematical Statistics, vol. 12, no. 2, p. 9, 1941.

[36] M. Begert, T. Schlegel, and W. Kirchhofer, "Homogeneous temperature and precipitation series of Switzerland from 1864 to 2000," International Journal of Climatology, vol. 25, no. 1, pp. 65-80, 2005.

[37] A. C. Costa and A. Soares, "Homogenization of climate data: review and new perspectives using geostatistics," Mathematical Geosciences, vol. 41, no. 3, pp. 291-305, 2008.

[38] E. Eris and N. Agiralioglu, "Homogeneity and trend analysis of hydrometeorological data of the eastern Black sea region, Turkey," Journal of Water Resource and Protection, vol. 4, no. 2, pp. 99-105, 2012.

[39] M. Javari, "Trend and homogeneity analysis of precipitation in Iran," Climate, vol. 4, no. 3, p. 44, 2016.

[40] J. B. Wijngaard, A. M. G. Klein Tank, and G. P. Können, "Homogeneity of 20th century European daily temperature and precipitation series," International Journal of Climatology, vol. 23, no. 6, pp. 679-692, 2003.

[41] L. Shen, L. Lu, T. Hu, R. Lin, J. Wang, and C. Xu, "Homogeneity test and correction of daily temperature and precipitation data (1978-2015) in north China," Advances in Meteorology, vol. 2018, Article ID 4712538, 17 pages, 2018.

[42] C. Yozgatligil and C. Yazici, "Comparison of homogeneity tests for temperature using a simulation study," International Journal of Climatology, vol. 36, no. 1, pp. 62-81, 2016.

[43] M. Gedefaw, H. Wang, D. Yan et al., "Trend analysis of climatic and hydrological variables in the Awash river basin, Ethiopia," Water, vol. 10, no. 11, p. 1554, 2018.

[44] K. Ahmed, S. Shahid, S. Shahid, T. Ismail, N. Nawaz, and X.-j. Wang, "Absolute homogeneity assessment of precipitation time series in an arid region of Pakistan," Atmósfera, vol. 31, no. 3, pp. 301-316, 2018.

[45] G. T. Oyerinde, F. C. C. Hountondji, D. Wisser et al., "Hydroclimatic changes in the Niger basin and consistency of local perceptions," Regional Environmental Change, vol. 15, no. 8, pp. 1627-1637, 2015.

[46] T. M. Reyna, "Using time series analysis to support the water resources management in the upper basin of the Suquía river," Pinnacle Environemtal \& Earth Sciences, vol. 2, no. 1, 2015.

[47] S. Tekleab, Y. Mohamed, and S. Uhlenbrook, "Hydro-climatic trends in the abay/upper Blue Nile basin, Ethiopia," Physics and Chemistry of the Earth, Parts A/B/C, vol. 61-62, pp. 32-42, 2013.
[48] D. Bekele, T. Alamirew, A. Kebede, G. Zeleke, and A. M. Melese, "Analysis of rainfall trend and variability for agricultural water management in Awash river basin, Ethiopia," Journal of Water and Climate Change, vol. 8, no. 1, pp. 127-141, 2017.

[49] M. H. Daba, "Sensitivity of SWAT simulated runoff to temperature and rainfall in the upper Awash sub-basin, Ethiopia," Hydrology: Current Research, vol. 9, no. 1, 2018.

[50] H. M. Kang and F. Yusof, "Homogeneity tests on daily rainfall series," International Journal of Contemporary Mathematical Sciences, vol. 7, no. 1, pp. 9-22, 2012.

[51] F. Che Ros, H. Tosaka, L. M. Sidek, and H. Basri, "Homogeneity and trends in long-term rainfall data, Kelantan river basin, Malaysia," International Journal of River Basin Management, vol. 14, no. 2, pp. 151-163, 2016.

[52] H. Alexandersson, "A homogeneity test applied to precipitation data," Journal of Climatology, vol. 6, no. 6, pp. 661-675, 1986.

[53] M. Martínez, C. Serra, A. Burgueño, and X. Lana, "Time trends of daily maximum and minimum temperatures in Catalonia (ne Spain) for the period 1975-2004," International Journal of Climatology: A Journal of the Royal Meteorological Society, vol. 30, no. 2, pp. 267-290, 2010.

[54] A. M. G. Klein Tank, J. B. Wijngaard, G. P. Können et al., "Daily dataset of 20th-century surface air temperature and precipitation series for the European climate assessment," International Journal of Climatology, vol. 22, no. 12, pp. 1441-1453, 2002.

[55] M. L. Tan, N. Samat, N. W. Chan, A. J. Lee, and C. Li, "Analysis of precipitation and temperature extremes over the Muda river basin, Malaysia," Water, vol. 11, no. 2, p. 283, 2019.

[56] K. H. Hamed and A. R. Rao, "A modified Mann-Kendall trend test for autocorrelated data," Journal of Hydrology, vol. 204, no. 1-4, pp. 182-196, 1998.

[57] M. G. Kendall and A. Stuart, The Advanced Theory of Statistics, Griffin, London, UK, 1973.

[58] H. B. Mann, "Nonparametric tests against trend," Econometrica, vol. 13, no. 3, pp. 245-259, 1945.

[59] C. Goossens and A. Berger, "How to recognize an abrupt climatic change?" Abrupt Climatic Change, pp. 31-45, Springer, Berlin, Germany, 1987.

[60] J. Li, W. Wu, X. Ye et al., "Innovative trend analysis of main agriculture natural hazards in China during 1989-2014," Natural Hazards, vol. 95, no. 3, pp. 677-720, 2018.

[61] Z. Şen, "Hydrological trend analysis with innovative and overwhitening procedures," Hydrological Sciences Journal, vol. 62, no. 2, pp. 294-305, 2016.

[62] E. M. Blyth, A. Martinez-de la Torre, and E. L. Robinson, "Trends in evapotranspiration and its drivers in Great Britain: 1961 to 2015," Hydrology and Earth System Sciences Discussions, pp. 1-47, 2018.

[63] M. Shadmani, S. Marofi, and M. Roknian, "Trend analysis in reference evapotranspiration using Mann-Kendall and Spearman's rho tests in arid regions of Iran," Water Resources Management, vol. 26, no. 1, pp. 211-224, 2011.

[64] F. Tosunoglu and O. Kisi, "Trend analysis of maximum hydrologic drought variables using Mann-Kendall and Sen's innovative trend method," River Research and Applications, vol. 33, no. 4, pp. 597-610, 2017.

[65] K. Xu, J. D. Milliman, and H. Xu, "Temporal trend of precipitation and runoff in major Chinese rivers since 1951," Global and Planetary Change, vol. 73, no. 3-4, pp. 219-232, 2010. 
[66] M. Gocic and S. Trajkovic, "Analysis of changes in meteorological variables using Mann-Kendall and Sen's slope estimator statistical tests in Serbia," Global and Planetary Change, vol. 100, pp. 172-182, 2013.

[67] D. R. Helsel and R. M. Hirsch, Statistical Methods in Water Resources, Vol. 49, Elsevier, Amsterdam, Netherlands, 1992.

[68] P. K. Sen, "Estimates of the regression coefficient based on Kendall's tau," Journal of the American Statistical Association, vol. 63, no. 324, pp. 1379-1389, 1968.

[69] M. Tsega and D. Tibebe, "Homogeneity tests on rainfall records for selected meteorological stations in Ethiopia," Advanced Journal of Agricultural Research and Reviews, vol. 2, no. 3, p. 9, 2018.

[70] Ö. Kişi, C. A. G. Santos, R. M. da Silva, and M. ZounematKermani, "Trend analysis of monthly streamflows using Şen's innovative trend method," Geofizika, vol. 35, no. 1, pp. 53-68, 2018.

[71] A. E. Lawin, C. Manirakiza, and B. Lamboni, "Trends and changes detection in rainfall, temperature and wind speed in Burundi," Journal of Water and Climate Change, vol. 10, no. 4, pp. 852-870, 2018.

[72] A. Malik, A. Kumar, P. Guhathakurta, and O. Kisi, "Spatialtemporal trend analysis of seasonal and annual rainfall (1966-2015) using innovative trend analysis method with significance test," Arabian Journal of Geosciences, vol. 12, no. 10, p. $328,2019$.

[73] G. Mallya, S. Tripathi, and R. S. Govindaraju, "Chapter 6-detection of temporal changes in droughts over Indiana," Trends and Changes in Hydroclimatic Variables, pp. 305-360, Elsevier, Amsterdam. Netherlands, 2019.

[74] J. Mohd Wani, V. K. Sarda, and S. K. Jain, "Assessment of trends and variability of rainfall and temperature for the district of Mandi in Himachal Pradesh, India," Slovak Journal of Civil Engineering, vol. 25, no. 3, pp. 15-22, 2017.

[75] M. Mudelsee, "Trend analysis of climate time series: a review of methods," Earth-Science Reviews, vol. 190, pp. 310-322, 2019.

[76] Z. Nouaceur and O. Murărescu, "Rainfall variability and trend analysis of annual rainfall in north Africa," International Journal of Atmospheric Sciences, vol. 2016, Article ID 7230450, 12 pages, 2016.

[77] A. d. A. Nunes, E. J. d. A. Pinto, and M. B. Baptista, "Detection of trends for extreme events of precipitation in the Metropolitan region of Belo horizonte through statistical methods," RBRH, vol. 23, 2018.

[78] A. B. Pal, D. Khare, P. K. Mishra, and L. Singh, "Trend analysis of rainfall, temperature and runoff data: a case study of rangoon watershed in Nepal," International Journal of Students' Research in Technology \& Management, vol. 5, no. 3, p. 21, 2017.

[79] S. Hadi Pour, A. Abd Wahab, S. Shahid, X. Wang, and $\mathrm{X}$. Wang, "Spatial pattern of the unidirectional trends in thermal bioclimatic indicators in Iran," Sustainability, vol. 11, no. 8, p. $2287,2019$.

[80] M. S. Nashwan and S. Shahid, "Spatial distribution of unidirectional trends in climate and weather extremes in Nile river basin," Theoretical and Applied Climatology, vol. 137, pp. 1181-1199, 2018.

[81] S. Kumar, V. Merwade, J. L. Kinter III, and D. Niyogi, "Evaluation of temperature and precipitation trends and longterm persistence in CMIP5 twentieth-century climate simulations," Journal of Climate, vol. 26, no. 12, pp. 4168-4185, 2013.
[82] S. Sagarika, A. Kalra, and S. Ahmad, "Evaluating the effect of persistence on long-term trends and analyzing step changes in streamflows of the continental United States," Journal of Hydrology, vol. 517, pp. 36-53, 2014. 